\title{
Pesticide risk assessment in honeybees: toward the use of behavioral and
}

reproductive performances as assessment endpoints

5 Lena Barascou ${ }^{1,2, \ddagger}$, Jean-Luc Brunet ${ }^{1,2}$, Luc Belzunces ${ }^{1,2}$, Axel Decourtye ${ }^{2,3}$, Mickael Henry ${ }^{1,2}$, Julie Fourrier $^{2,3}$, Yves Le Conte ${ }^{1,2}$, Cedric Alaux ${ }^{1,2,+}$

${ }^{1}$ INRAE, Abeilles et Environnement, Avignon, France

${ }^{2}$ UMT PrADE, Avignon, France

${ }^{3}$ ITSAP-Institut de l'abeille, Avignon, France

^Corresponding authors: lena.barascou@inrae.fr, cedric.alaux@inrae.fr 


\title{
Highlights
}

- There is a gap between new evidence of pesticide toxicity in honeybees and regulatory toxicological bioassays

- Current endpoints should be complemented with behavioral and reproductive endpoints

- We review such endpoints and discuss their possible use in pesticide risk assessment

- There is a need to translate toxicological research studies into regulatory test methods

\begin{abstract}
The growing gap between new evidence of pesticide toxicity in honeybees and conventional toxicological assays recommended by regulatory test guidelines emphasizes the need to complement current lethal endpoints with sublethal endpoints. In this context, behavioral and reproductive performances have received growing interest since the 2000s, likely due to their ecological relevance and/or the emergence of new technologies. We review the biological interests and methodological measurements of these predominantly studied endpoints and discuss their possible use in the pesticide risk assessment procedure based on their standardization level, simplicity and ecological relevance. It appears that homing flights and reproduction have great potential for pesticide risk assessment, mainly due to their ecological relevance. If exploratory research studies in ecotoxicology have paved the way toward a better understanding of pesticide toxicity in honeybees, the next objective will then be to translate the most relevant behavioral and reproductive endpoints into regulatory test methods. This will require more comparative studies and improving their ecological relevance. This latter goal may be facilitated by the use of population dynamics models for scaling up the consequences of adverse behavioral and reproductive effects from individuals to colonies.
\end{abstract}

Keywords: Apis mellifera; toxicology; hazard assessment; sublethal endpoints; regulatory test methods 


\section{Introduction}

Plant protection products, also referred to as phytopharmaceutical products or pesticides, consist of active substances (with safeners or synergists) intended to protect plants against harmful organisms (e.g. insects, fungi) or prevent the growth of undesired plants (herbicides). Pesticides must be evaluated and approved by regulatory authorities before registration. Besides providing data on the physical and chemical properties, the mode of action and the efficacy, pesticide registration applications must include data on the product's fate in the environment, as well as its toxicity for humans and non-target organisms. Regulatory authorities can then provide an assessment of the risk presented by the pesticide and determine to what extent it is safe for human and environmental health.

As part of the overall risk assessment procedure, OECD (Organization for Economic Co-operation and Development) and EPPO (European and Mediterranean Plant Protection Organization) test guidelines require toxicological data on honeybees (Apis mellifera). Until very recently, honeybees were the only insect pollinator used for pesticide risk assessment and were considered a surrogate species for non-Apis bees (EPPO, 2010a, 2010b). Likely because they are relatively easy to rear, their biology has been wellstudied, and they are one of the most important pollinators worldwide (Ghazoul, 2005; Klein et al., 2007). Honey bees forage within large areas around their hives and are thus likely to be exposed to several pesticides either directly (collecting nectar, pollen and water) or indirectly (sharing food with nestmates: larvae and adult worker bees, queen and drones).

Over the last decades, progress in research has been made in evaluating the risk that pesticides pose to honeybees by assessing the toxicological effects. Extensive empirical data have therefore accumulated on pesticide effects, which have been compiled in several reviews (see for instance Alkassab and Kirchner, 2017; Belzunces et al., 2012; Blacquière et al., 2012; Cullen et al., 2019; Desneux et al., 2007; Johnson, 2015; Poquet et al., 2016). Toxic effects vary depending on the dose/concentration, modes of action and exposure routes. More importantly, a new range of endpoints (biological parameters used to evaluate the toxicity of a chemical) have been used to identify sublethal effects (e.g. impairment of cognitive capacities, foraging activity, communication, and reproductive performances) (Decourtye et al., 2003; Kairo et al., 2017b; Karahan et al., 2015; Zhang et al., 2020b). In addition, small doses or 
concentrations that were believed to be sublethal in laboratory bioassays proved to be lethal in field conditions (e.g. Henry et al 2012).

These recent findings raise concerns about risk assessment procedures for pesticide registration, which mainly focus on lethal effects. First, while sublethal effects do not directly cause the death of individual bees, they may impair individual and colony performance, as well as their pollination services (Meikle et al., 2016; Prado et al., 2019; Tison et al., 2017; Woodcock et al., 2017). Second, exposures to pesticides, previously identified as nonlethal in lab assays, caused high mortality in natural conditions (Henry et al 2012). Therefore, current test procedures do not appear sufficient to protect honey bees. This growing gap between new evidence of pesticide toxicity (e.g. sublethal effects) in honeybees and the conservative toxicological bioassays needed for pesticide approval contribute to the controversy between stakeholders, policymakers, environmentalists and scientists (Durant, 2020; Sgolastra et al., 2020; Storck et al., 2017; Thompson and Maus, 2007). In order to fill this gap and better assess the threat of pesticides to honeybees, we emphasize the need to complement current endpoints (essentially based on $\mathrm{LD}_{50}$ - dose at which $50 \%$ of the individuals die) with sublethal endpoints. We focus on behavioral and reproductive endpoints, which have received increasing interest due to their ecological relevance and the technical advances made in their recording. Furthermore, pesticides can have low-dose effects on these endpoints.

We review such endpoints and discuss which ones could be considered for pesticide risk assessments based on several criteria, such as the possibility of standardization, their monitoring simplicity and their ecological relevance. Finally, we highlight the future challenges that need to be addressed to better integrate and use these endpoints in pesticide risk assessment.

\section{The rise of behavioral and reproductive endpoints in response to the risks associated with low exposure to pesticide}

In the current regulatory framework for honeybees, the effects of pesticides are assessed by standard regulatory tests, in a tiered approach (EFSA, 2013; EPPO, 2010a, 2010b). At a low tier, laboratory tests on active substances or formulated products are used on individual bees that are representative of 
different life stages (larval and adult). This is the first mandatory step that includes an acute toxicity test after oral or contact exposure in adults (OECD, 1998a, 1998b) and larvae (OECD, 2013), and a chronic toxicity test on adults over 10 days (OECD, 2017). For acute toxicity tests, the $\mathrm{LD}_{50}$ is determined. Then, if a risk is identified as a result of this first step, supplementary tests are required at a higher tier (semifield and field tests). For instance, several key parameters of honeybee colony state may be measured, besides bee mortality, like foraging activity and honey and brood production (EPPO 2010a, 2010b). However, particular attention should be paid to sublethal effects to better identify risk, and avoid situations where a pesticide might not undergo tests at a higher tier because of its supposedly low toxicity under current laboratory tests. We therefore need individual-level endpoints that are more reliable and relevant.

The primary endpoint of laboratory tests is the $\mathrm{LD}_{50}$, which suggests that the dose-response for a given substance follows either a proportional or a threshold dose-response relationship. However, there are several lines of evidence for multiphasic relationships. For instance, Suchail et al. (2001) found that mortality rates in response to exposure to imidacloprid (neonicotinoid insecticide) increased for low doses, decreased for medium doses, and then increased in a dose-dependent manner for higher doses. This suggests that significant effects can occur at doses lower than the ones used in mortality bioassays $\left(\mathrm{LD}_{50}\right.$ tests) or under the NOEL (No Observed Effect Level). Such effects may occur in environments contaminated by low doses of pesticide residues and are usually sublethal with adverse effects on development (Dai et al., 2010), metabolism (Decourtye et al., 2004a), immunity (Aufauvre et al., 2014), behavior (Yang et al., 2008), and reproduction (Kairo et al., 2016). This may be translated into potential 115 risk to colonies. For instance, the immunosuppression caused by clothianidin has been shown to promote the replication of the deformed wing virus (Di Prisco et al., 2013), a virus that has been frequently linked to colony losses (Grozinger and Flenniken, 2019).

Additionally, comparing effects observed in laboratory tests to field observations raised concerns about the underestimation of pesticide toxicity at sublethal doses, as illustrated by studies of aquatic populations of macroinvertebrates (Rasmussen et al., 2012; Schäfer et al., 2012) (e.g. for Daphnia magna, the level of exposure to pesticides was found to be 10 to 100 times more harmful than that predicted by the EU's "first tier" risk assessment). In honeybees, these concerns were verified in field 
tests by recording the homing success of bees exposed to a dose of thiamethoxam assumed to be sublethal based on regulatory tests (nearly four times lower than the $\mathrm{LD}_{50}$ ). This sublethal dose caused significant failure in homing flight which could potentially decrease colony survival (Henry et al., 2015, 2012). This discrepancy between the laboratory and the field could be explained by the differences between the safe, non-challenging conditions of the laboratory assays and the environmentally challenging conditions of the field.

The underestimation of risks related to low doses and the striking mismatch between laboratory and field tests highlight the need to complement the current regulatory evaluation of pesticides, essential for performing a preliminary screening of toxic effects, with sublethal and more ecologically-relevant tests. In this context, the measurement of behavioral and reproductive performances in ecotoxicity tests has become increasingly popular. Notably, a keen interest in behavioral effects has recently been tracked in the US EPA ECOTOX database with records of 17324 and 13809 measurements for aquatic and terrestrial organisms, respectively (Ågerstrand et al., 2020). As explained by Ågerstrand et al. (2020), the relevance of behavioral endpoints is driven by several advantages, which we believe are also valid for reproductive endpoints. They improve the ecological relevance of pesticide risk assessment because they add ecological realism to the test conditions and help connect organismal response to populations, which are generally the ultimate protection goal (Rudén et al., 2017). These individual-level endpoints therefore should help predict effects on higher levels of biological organization (i.e. colonies for honeybees). In addition, pesticides can have low-dose effects on these endpoints, which can thus provide a more effective assessment of risks associated with low contamination levels of the environment as compared to the current mortality endpoints. Finally, regarding behavioral measurements, the emergence of new tracking technologies has increased the rate of acquisition and amount of in situ monitoring data (Kays et al., 2015). More importantly, such technology enables us to improve the robustness and precision of measurements and thus decrease the variability of ecotoxicological data, which can be relatively high when obtained through basic observations. The improved reproducibility of toxicity tests is notably essential for the regulatory assessments of pesticides. 


\section{Overview of behavioral and reproductive performances as assessment endpoints in}

\section{honeybees}

The investigation of pesticide effects at sublethal doses or concentrations in honeybees began in earnest in the 2000s (Fig. 1A). Since then, behavioral and reproductive endpoints have been more frequently included in toxicological research studies. The goal here is not to provide a systematic review but rather an overview of the main individual-based behavioral and reproductive endpoints by describing $(i)$ their biological interests, (ii) the measurement methodologies and (iii) the main observed effects. For that purpose, we focused on the most studied endpoints (used in more than five research studies) that were grouped into the seven following categories: grooming, locomotion, learning and memory, foraging, homing flight, waggle dance and reproduction (Fig. 1B).

\subsection{Grooming}

The ability of worker bees to clean themselves (self-grooming) and their nestmates (allo-grooming) contributes to the prevention of the spread and multiplication of parasites and pathogens within the colony and is therefore related to colony health (Evans and Spivak, 2010). Bees notably groom themselves or another bee in order to remove parasites from their body with their legs and mandibles. Since grooming mainly involves motor functions, neurotoxic pesticides have been hypothesized to alter the performance of these behaviors. Grooming behavior has traditionally been evaluated by marking and tracking bees in observation hives or petri dishes. Only two studies investigated the influence of pesticides on allo-grooming; both reported a lack of effect after exposure to imidacloprid, bioinsecticides (essential oil and geraniol; Santos et al., 2018), thiacloprid and tau-fluvalinate (Retschnig et al., 2015). Conversely, self-grooming performance appeared more sensitive to intoxication. While de Mattos et al. (2017) found a reduction in the duration of self-grooming after exposure to acaricides (coumaphos, amitraz and tau-fluvalinate), bees intoxicated with pesticides, such as neonicotinoids (imidacloprid, thiamethoxam, clothianidin, dinotefuran) (Williamson et al., 2014), acetylcholinesterase inhibitors (Williamson et al., 2013), permethrin (Cox and Wilson, 1984) and oxalic acid (Schneider et al., 2012), showed an increased propensity to perform self-grooming. However, two toxicological 
studies found no effect of pyrethroids (including tau-fluvalinate and permethrin) (Oliver et al., 2015), imidacloprid or bioinsecticides on self-grooming (Santos et al., 2018).

\subsection{Locomotion}

Insecticides, such as pyrethroids and neonicotinoids, which target the voltage-sensitive sodium channels or nicotinic acetylcholine receptors, respectively, may directly impair neuronal transmission, muscle activation (Hirata, 2016), and therefore locomotor activity (walking, flying). Moreover, some pesticides, like fungicides, may reduce energy production (Degrandi-Hoffman et al., 2015) and therefore affect locomotion, especially flight capacity, as flying is one of the most intense and energy-demanding physiological processes in insects (Dudley, 2000).

Walking locomotion experiments typically monitor the walking pattern of individual bees in standardized open field arenas and may reveal in-hive worker impairments during ongoing tasks in the colonies. Movement pattern is most often monitored by means of automated video tracking systems coupled with an ad-hoc image processing software that detects on a continuous basis the position of bees. Locomotion activity is typically indicated by the total covered distance or conversely by the length of time of immobility (Hesselbach and Scheiner, 2018), also termed prostration (Kadala et al., 2019) or lethargy (Williams et al., 2020), during a fixed period (typically between 3 to $15 \mathrm{~min}$ ), and more recently, by circadian rhythms (Delkash-Roudsari et al., 2020). More subtle metrics may document abnormal trembling or convulsive movements of legs and wings (Aliouane et al., 2009), as well as the loss of the righting reflex (Oliver et al., 2015). Experiments may be either conducted in complete darkness using infrared recording systems (Teeters et al., 2012), or in the presence of a nearby light stimuli to explore the effect of exposure to pesticides on phototaxis (Charreton et al., 2015; El Hassani et al., 2008, 2005; Tosi and Nieh, 2017). Additionally, when placed vertically, the arena experiment may reveal a potential interaction with geotaxis (El Hassani et al., 2008, 2005). Finally, more advanced versions of the experiments may introduce food or conspecifics into the arena to further implement food attraction or social interactions as a part of the walking pattern (Ingram et al., 2015; Teeters et al., 2012).

Flying locomotion is more difficult to document. It requires more sophisticated apparatus like flight mills, whereby the tested bees are tethered to a balanced arm and allowed to fly circularly around an 
axis (Tong et al., 2019; Tosi et al., 2017). Alternatively, bees may be harnessed to a fixed support and exposed to air flow and optic flow stimuli in order to elicit flight (Liao et al., 2019). Flight experiments typically document flight duration until exhaustion, total covered distance, as well as average flight velocity.

Most of the studies reported significant locomotion deficits in bees exposed to pesticides, particularly pyrethroids and neonicotinoids. Walking experiments typically reported increased immobility (Aliouane et al., 2009; El Hassani et al., 2005), righting difficulties (Williamson et al., 2014) and shorter walking distances (Charreton et al., 2015; Ingram et al., 2015). However, common patterns are difficult to identify across studies due to the broad variety of experimental designs and peculiarities related with bee age (Charreton et al., 2015), topical vs. oral exposure (El Hassani et al., 2008, 2005), exposure duration (Williams et al., 2020) or timescale after exposure (Kadala et al., 2019). Similarly, if a reduction in flying capacities was generally reported by experiments with flight mills (Liao et al., 2019; Tong et al., 2019; Tosi et al., 2017), depending on the type of exposure, opposite effects could also be induced on specific flight traits (Tong et al., 2019).

\subsection{Learning and memory}

One commonality of nearly all studies investigating pesticide effects on learning and memory in honeybees is the use of a Pavlovian conditioning protocol, the olfactory conditioning of the "Proboscis Extension Response" (PER). Other paradigms for testing learning and memory (e.g., habituation, visual learning, aversive learning) are available, but have been less used in toxicological studies (Armengaud et al., 2002; Guez et al., 2001; Lambin et al., 2001; Muth and Leonard, 2019; Urlacher et al., 2016). The olfactory PER conditioning protocol is notably useful for excluding confounding variables and experimental noise in learning assays. It enables one to reproduce, under laboratory conditions, the conditioning process occurring on the flower (Menzel and Müller, 1996). Whereas bees initially exhibit PER (unconditioned response) to antennal contact with sucrose (reward), they learn to initiate PER in response to an odor alone (conditioned response) when this contact was previously paired with this odor (Giurfa and Sandoz, 2012). Although Muth and Leonard (2019) proposed an original method of PER conditioning in free-flying bees, PER experiments are commonly carried out on restrained individuals 
in the laboratory. The PER protocol has proven very useful in addressing many aspects of bee learning, such as extinction learning, and stimulus generalization and discrimination (Giurfa and Sandoz, 2012). Multiple authors have investigated the effects of pesticides with the PER assay with varying parameters (e.g. pesticide concentration, honeybee age, season, subspecies, and trial number, inter-trial interval and performance measures). Underlying these toxicological studies is that sublethal doses of neurotoxic pesticide affect the learning and memory of bees (Taylor et al., 1987), thereby reducing individual foraging efficiency. This explains why, besides some studies on fungicide or insect-growth regulators, PER assays were mostly used to test insecticides with neurotoxic activity, (Abramson et al., 2004; Decourtye et al., 2004b). As of now, nearly thirty pesticides have been tested with this bioassay; the majority of studies being performed with the active ingredient (rarely the 'ready to use' formulation of the farmer, except for (Abramson et al., 2012; Tison et al., 2017b)). By building on this strong background, Siviter et al. (2018) conducted a meta-analysis to quantify pesticide effects on learning and memory. They showed that both neonicotinoid and non-neonicotinoid pesticides cause significant decreases in learning and memory capacity at field-realistic exposure levels and under both chronic and acute exposure. The impacts at the adult stage of larval exposure remain relatively unexplored (Papach et al., 2017; Yang et al., 2012). However, Siviter et al. (2018) suggested that learning performances of bees could be more sensitive to pesticides when exposed during larval development.

\subsection{Foraging activity}

Foraging consists of repeated visits to different flowers for collecting pollen and nectar in an average radius of 1.5 to $5 \mathrm{~km}$ (up to $10 \mathrm{~km}$ if the floral resources are scarce) (Beekman and Ratnieks, 2000; Steffan-Dewenter and Kuhn, 2003). Typically performed by older bees foraging involves many complex cognitive functions such as learning (e.g. visual and olfactory stimuli of flowers, landscape characteristics), orientation and navigation (Dyer and Gould, 1981; Menzel, 1999), and is also energetically costly. Because foragers are usually the first bees to encounter pesticides while visiting flowers and can bring back pesticide-contaminated pollen and nectar to the hive, foraging is considered as the starting point of colony intoxication. For these reasons (frequent risk of exposure, behaviorally challenging tasks), the influence of pesticides on foraging has long been investigated. 
To be able to record individual-based foraging activity, experiments are generally performed in a flight tunnel and with a feeder on which bees can forage. The frequency of visits to a feeder by forager bees (marked with a color dot on the thorax), as well as the time period between visits, can then be determined. Exposure to pesticides can be carried out in different ways, either by providing colonies with a pesticide-contaminated sugar solution (Ramirez-Romero et al., 2005; Yang et al., 2008) or individually by submitting the bees to an acute treatment (topical or oral route) (Guez et al., 2005; Karahan et al., 2015). A decrease in visit frequency and an increase in time period between visits were generally observed upon exposure to pesticides (Karahan et al., 2015; Ramirez-Romero et al., 2005; Yang et al., 2008). However, depending on the dose, opposite effects could be observed. For instance, doses of 10 and $50 \mathrm{ng}$ of methyl parathion induced a decrease and an increase in the frequency of visits to the feeder, respectively (Guez et al., 2005). Only recently, the emergence of new technologies (Radio Frequency Identification - RFID, optic bee counters) has enabled more detailed analysis of foraging activity and a move from non-challenging foraging activity in a flight tunnel, under controlled conditions, to field foraging activity (Decourtye et al., 2011; Streit et al., 2003). By recording, on a continuous basis, the activity of individual bees at the hive entrance (time of each exit and entrance of tagged bees), these technologies allow access to different individual foraging traits, such as the number and duration of trips (daily and total) or the age at the onset of foraging. Apart from an early study, which demonstrated a short-term reduction in foraging activity and longer foraging trips between the hive and a feeder after exposure to clothianidin and imidacloprid (Schneider et al., 2012), no clear effect was observed on the daily number and duration of trips in the field when bees were exposed, to fieldrealistic doses of insecticides (Colin et al., 2019b; Hesselbach et al., 2020). However, a significant premature onset of foraging was often reported (Colin et al., 2019b; Hesselbach et al., 2020; Shi et al., 2020). Precocious foraging was then accompanied by a reduction in lifespan and total foraging activity. The onset of foraging was delayed in bees exposed to mixtures of pesticides at very low doses (from 100 to 10000 times lower than their LD $_{50}$ values) (Prado et al., 2019); such bees exhibited a lowered daily foraging activity. Scaling up to a higher tier of study, Henry et al., (2015) investigated the foraging activity and mortality of bees originating from colonies placed near fields of rape oilseed treated with thiamethoxam. Although no modification in foraging traits was reported, an increased mortality rate, 
likely due to failure in homing flights, was observed. Finally, foraging efficiency was analyzed by Prado et al. (2019) by measuring the amount of nectar and pollen collected by bees (exposed to pesticide at emergence): no effect of exposure to pesticides was found on nectar foraging but individual foragers returned to the colonies with a lower amount of pollen. Morfin et al. (2019) also observed the impairment of pollen foraging in bees exposed to clothianidin at the larval stage. This higher sensitivity of pollenforaging bees, as opposed to nectar foraging, has also previously been reported for bumblebees following exposure to pesticides (Feltham et al., 2014; Gill et al., 2012), and therefore seems to be a hallmark of stressed bees (Bordier et al., 2018; Lach et al., 2015).

\subsection{Homing flight}

Over the last thirty years, sublethal doses of pesticides have been suspected to affect orientation and homing flight of foragers. This concern originated with the depopulation of hives observed by beekeepers near fields sowed with seed-dressing-treated crops. Orientation performance of foragers exposed to low doses of an insecticide were initially investigated using a complex maze device (Decourtye et al., 2009). This device relies on associative learning between a visual mark to navigate in the maze and a reward of sugar solution (Zhang et al., 1999). Indeed, a bee exposed to a pesticide during foraging trips may incorrectly learn and/or memorize visual patterns for navigation, causing disorientation and bee loss due to homing failure (Desneux et al., 2007). These experiments are based on the use of limited cues whereas navigation in natural conditions relies on a combination of several guidance mechanisms and cognitive functions (see above). More realistic experimental situations were designed and showed an impact of insecticides on the homing performances of foragers by recording the flight activity between a feeder and the colony located $8 \mathrm{~m}$ away in semi-field conditions (Vandame et al., 1995) or $500 \mathrm{~m}$ away in field conditions (Bortolotti et al., 2003).

More recently, Matsumoto (2013) showed an increase in the proportion of homing failure of foragers, released $500 \mathrm{~m}$ away from the colony, when exposed to sublethal doses of neonicotinoid or pyrethroid insecticides. However, the number of individuals monitored simultaneously and the time span of the observations may present experimental difficulties in these studies using marked bees (paint or colored, numbered tags) (Decourtye et al., 2011; Pahl et al., 2011). The emergence of automatic tracking 
technology helped to solve these problems and study the effects of pesticides on free-ranging foragers in field conditions. Using RFID technology with continuous recording (48 hours), Henry et al. (2012) showed that foragers released $1 \mathrm{~km}$ away from their colony returned to the hive at a significantly lower rate when exposed to a sublethal dose of thiamethoxam. Such effects were confirmed with colonies placed near rape oilseed crop originating from seed-dressing treated with Cruiser ${ }^{\circledR}$-containing thiamethoxam (Henry et al., 2015). Foragers originating from these colonies and tracked with RFID microchips disappeared at a faster rate with increasing field exposure (e.g. increased mortality rate of $10 \%$ due to non-returning bees per $15 \mathrm{ha}$ of treated crop in a radius of $1 \mathrm{~km}$ around the colony) and this excess mortality increased over time. The homing flight failure might be explained by impairments to flight capacity (e.g. motor functions) (Tosi et al., 2017) and cognitive functions, such as the retrieval of previously learned information (e.g. visual cues) (Fischer et al., 2014; Tison et al., 2016). These assumptions are further supported by the fact that negative effects on homing performances were more pronounced at lower temperatures (below $28^{\circ} \mathrm{C}$ ) and in environments with a greater density of landmarks (e.g. hedges, forest borders) (Henry et al., 2014). Finally, the health status of colonies and especially varroa infestation levels may also impact the homing performances of foragers. Experimental data and predictive modelling show a three times greater effect of thiamethoxam on foragers originating from colonies infested by 5 varroa mites per 100 bees as compared to foragers from varroa-free colonies (Monchanin et al., 2019).

\subsection{Waggle dance}

When returning from a food rich area, successful foragers share information about its distance and direction through body movements to recruit naive bees (Dyer, 2002). The dancing bee notably performs repeated waggle dances (loops with a shape of a ' 8 ') if the food source is located at more than 50 meters away. In the waggle dance, composed of a waggle and return phase, the axis of the ' 8 ' represents the direction of the food source relative to the sun position, and the number of waggle runs inform receivers of its distance. Waggle dance performance therefore requires detecting and integrating into the central nervous system several environmental parameters linked to spatial information, which are then encoded 
into body movements. Pesticides, and particularly insecticides, that target the nervous system, would have an expected impact on forager ability to communicate food location.

To decipher potential effects of pesticides, several components of the waggle dance can be measured, such as the number of loops, the angle of the dance, the duration of the waggle run and the frequency of the vibrations produced by the bees (Dyer, 2002). The simplest methods for studying the waggle dance are visual observation or video recording of a colony in an observation hive. Using such techniques, a precursor study by Schricker and Stephen (1970) reported a pesticide effect on the waggle dance, with changes in the dance angle in a stepwise fashion (instead of linearly) in bees exposed to parathion. Then, three studies, investigating the toxic effect of imidacloprid on the waggle dance, found a reduced number of dance circuits (Eiri and Nieh, 2012) and decreased precision of directional information (i.e. larger variance in the angle of the waggle phase) (Kirchner, 1999; Zhang et al., 2020a). A similar impairment of dance communication was found upon exposure to deltamethrin (Zhang et al., 2020b). A more automatic recording of waggle dance, based on the measurements of electrical fields, was developed by Greggers et al. (2013). They found that dancing bees emit low- (movements of the abdomen, 16Hz) and high-frequency (buzzing of the wings, $230 \mathrm{~Hz}$ ) electrical fields, which allowed them to determine the number of waggle runs (Greggers et al., 2013). Using this technique, Tison et al. (2016) found a significant reduction in the number of waggle dances per hour in bees intoxicated by the neonicotinoid thiacloprid as compared to control bees.

\subsection{Queen and drone fertility}

As early as the 1960s, it was shown that exposure to chemicals can directly alter sexual behavior, mating success, sex ratio and fertility, notably through a decrease in spermatozoa viability and number. The pioneering study of Carson found that the organochlorine insecticide DDT

(Dichlorodiphenyltrichloroethane) causes reproductive injuries in birds, leading to a decline in their populations (Carson, 1962). Evidence for pesticide-induced reproductive toxicity in honeybees emerged 40 years later and was especially intriguing, given that the reproductive castes (queen and drones) are generally exposed to much lower concentrations of pesticides than worker bees. The queen and drones normally feed on food processed and supplied by workers, which can lead to exposure to concentrations 

$0.016 \%$ of the original pesticide concentration found in the diet consumed by workers bees (Böhme et al., 2018). However, they may be exposed during their development to higher levels of pesticides contained in the wax (Chauzat and Faucon, 2007; Mullin et al., 2010).

An impairment of queen fertility could translate into either a temporary or permanent absence of egg laying, or the laying of unfertilized eggs (drones), leading to poor colony development or ultimately colony failure (Büchler et al., 2013; Pettis et al., 1991; Rangel et al., 2013; vanEngelsdorp et al., 2013). Queen fertility after pesticide exposure has been investigated at both the colony and individual level. Colony-level examination usually consists of spiking the colony food supplement with pesticide and then analyzing queen egg-laying rate, brood area, hive population and food stocks (Colin et al., 2019a;

375 Meikle et al., 2016; Odemer and Rosenkranz, 2020; Woodcock et al., 2017). Using this procedure, colonies that were chronically exposed to the neonicotinoids, imidacloprid, thiamethoxam and clothianidin, demonstrated a significant decrease in queen egg-laying followed by reduced brood production (Sandrock et al., 2014; Wu-Smart and Spivak, 2016). Egg-laying reduction was notably associated with lower queen mobility (Wu-Smart and Spivak, 2016). Finally, colony foraging on rapeseed grown from seeds coated with thiamethoxam was followed by an increase in drone brood production (Henry et al., 2015). Such an effect could reflect either a higher investment of colonies in reproduction or an impairment of egg fertilization, the latter suggesting damage to spermatozoa in queens. These impairments caused by pesticides did not trigger colony collapse, even if a greater number of supersedures were reported (Bendahou et al., 1999; Sandrock et al., 2014). A major drawback of colony-level experiments is separating the direct and indirect effects of the pesticide on the observed reduction in egg-laying. The pesticide may be acting directly on the queen or may be decreasing worker foraging performance, resulting in reduced colony resources essential to brood production.

An alternative or complementary approach is to determine the effects of pesticides directly on queen physiology and fertility (body weight, the structure and the development of ovaries, the quantity and viability of spermatozoa stored in queen spermatheca). Negative impacts on ovary weight and fertility impairments were observed in young queens exposed during their development to coumaphos, fluvalinate and neonicotinoids via contaminated food (Haarmann et al., 2002; Pettis et al., 2004; 
Williams et al., 2015). Exposure to pesticides at the larval stage through contaminated wax also resulted in reduced queen egg-laying rate and attractiveness to workers (Walsh et al., 2020).

Regarding drones, the count and the viability rate of spermatozoa are two major biological parameters of fertility from which the quantity of spermatozoa available for queen fertilization can be deduced. Sperm count is determined using a microscopic cell count chambers or by flux cytometry analyses. The reproductive toxicity of pesticides in drones has also been investigated during the larval and adult stage. By supplying colonies with food contaminated with neonicotinoids during drone development (Ciereszko et al., 2017; Straub et al., 2016) or exposing drones during their development to beewax previously sprayed with miticides or agrochemicals (Fisher and Rangel, 2018), a consistent decrease in sperm viability and motility was found. To determine the reproductive toxicity of environmental concentration of the insecticide fipronil on adult drones, experiments were performed in semi-field conditions under insect-proof tunnels or in laboratory conditions. In semi- fields conditions, colonies foraged on a pesticide-contaminated feeder, whereas in laboratory conditions, drones were reared with worker bees in cages provided with pesticide-contaminated pollen. For all exposure methods, fipronil did not affect drone survival, maturity rates (number of drones that provided sperm after stimulation) and semen volumes, but significantly altered drone fertility by lowering spermatozoa concentration and viability, which reduced the amount of living sperm available for reproduction (Kairo et al., 2016, 2017b).

\section{Relevance of behavioral and reproductive performance as assessment endpoints}

The goal of this section is to provide general insights into the reliability and relevance of the different behavioral and reproductive endpoints in regards to the risk assessment procedure, i.e. to determine to what extent each of them is appropriate for chemical regulations. For that purpose, we primarily relied on criteria cited for test method validation in a regulatory hazard assessment context: simplicity, sensitivity, robustness, reproducibility (OECD, 2005). Simplicity implies that the endpoint method is relatively easy, and time- and cost-effective, for use in a regulatory context. Sensitivity indicates whether the method used to assess the endpoint can accurately detect dose-dependent effects. Robustness refers to the stability of responses to minor variations in experimental procedures and reproducibility to the 
ability to duplicate the results across laboratories/studies. We grouped both robustness and reproducibility criteria into one: the standardization level. The more toxicological studies have used a given method, the better we can evaluate its sensitivity and standardization level. Finally, we discussed the ecological relevance of endpoints, which indicates whether effects measured in individual bees can be related to consequences for colonies in field conditions.

\subsection{Test endpoints with low standardization level and uncertain ecological relevance: grooming,} waggle dance

The observation of bee behaviors has traditionally been conducted either directly by the observer or by means of video recording. If both methods are relatively easy to perform and do not require expensive materials, complexity in behavioral recording can arise from the targeted behavior itself. For instance, some behaviors may occur at a relatively low rate, making observations quite time-consuming to obtain enough sampling events, while others might be quite complex and require trained observers to record the full behavioral pattern. The waggle dance falls into both categories, which might explain why almost all toxicological studies focusing on the waggle dance tested only one dose or concentration. It is therefore currently not possible to determine whether pesticides can cause dose-dependent effects on the waggle dance. Similarly, few studies with grooming behavior as an endpoint used several doses or concentrations of pesticides. To our knowledge, only Williamson et al. (2014a; 2013) exposed bees to several sublethal doses of pesticides and reported effects on grooming in a dose-dependent manner. Regarding the robustness and reproducibility of methods, the waggle dance seems promising as revealed by three studies performed by different laboratories, which found similar effects of imidacloprid on waggle dance performance (Eiri and Nieh, 2012; Kirchner, 1999; Zhang et al., 2020b). However, some inconsistencies across studies testing the same substance were found for grooming behaviors. For instance, bees exposed to low doses of tau-fluvalinate showed either a decrease in grooming (de Mattos et al., 2017) or a lack of effect (Oliver et al., 2015). Such a discrepancy might be due to variability in experimental conditions (duration of exposure, dose, size of bee groups...) rather than to the recording of the behavior itself, which is rather straightforward. 
The main shortcoming for the use of these endpoints in pesticide risk assessment might be the limited extrapolation of effects on the consequences for the colonies. Grooming is essential to colony hygiene, but to what extent a decrease or increase in grooming performance of individual bees will affect colony development and survival, is largely unknown. Regarding the waggle dance, several studies have attempted to quantify the benefits of spatial information on colony foraging success. Schürch and Grüter (2014) found, via agent-based simulations, that spatial information was beneficial in the long-term in almost all ecological conditions, but it remains to be empirically validated. In reality, in experimental studies, the benefits were often null or occurred only in very specific habitats. For instance, benefits were observed in Asian tropical habitats but not in temperate habitats (Dornhaus and Chittka, 2004), in the winter or in urban areas (Sherman and Visscher, 2002), and then, only in habitats with high floral species richness and dense floral patches (Donaldson-Matasci and Dornhaus, 2012). Overall, these studies suggest that pesticide-induced disoriented dances might not have a clear impact on foraging success of the colony.

4.2. Test endpoints with high standardization level but lower ecological relevance: learning/memory, locomotion

The high interest in PER conditioning for evaluating pesticide effects on learning and memory can be explained by its simplicity. The method benefits from 60 years of methodological and conceptual development (Giurfa and Sandoz, 2012), is cheap, does not require specific technical expertise, and provides fast results for a large number of individuals. Most importantly, after reviewing the dozens of toxicological studies that used PER conditioning and taking into account possible technical bias across laboratories, Siviter et al. (2018) found that size effects on both learning and memory were robust between studies. Therefore, PER conditioning seems to provide reliable data for a wide range of doses and application procedures, which makes it a serious endpoint candidate for chemical regulation policy. The main weakness of PER conditioning is its ecological relevance. Drawing general conclusions about the impacts in field conditions of poor learning performances measured in the laboratory is challenging (Decourtye and Pham-Delègue, 2002; Thompson, 2003). Since cognitive abilities can directly affect functional behaviors (see Morand-Ferron et al., 2016 for a review), an impairment of cognitive 
capacities is expected to affect honeybee foraging performance. However, while reversal learning performance is associated with foraging experience (cumulated foraging time) (Cabirol et al., 2018), it remains unclear whether and how bee cognitive abilities contribute to individual foraging success and efficiency, and ultimately to colony performance. In bumblebees no difference in the rate of food collection and the number of foraging trips per day was found between fast and slow learners (Evans et al., 2017). There is a lack of studies using exposure methods that attempt to mimic field realistic scenarios. Therefore, the extrapolation of PER conditioning results to individual and colony foraging success is a key challenge that needs to be addressed in regard to its selection as an assessment endpoint. Methods for analyzing potential locomotor disabilities upon exposure to pesticides also proved to be sensitive since several studies were able to detect dose-dependent effects on bee locomotion (e.g. significant differences between exposures differing by 2 to 10-fold in dose) (Ingram et al., 2015; Tosi and Nieh, 2017; Williamson et al., 2014). The robustness and reproducibility of methods is more difficult to assess due to a relatively low number of research studies. However, the recording of bee activity in an arena is rather straightforward: it simply requires a camera and data that can be analyzed in a semi-automatic way (Kadala et al., 2019). The standardization of endpoints measured with the flight mill is also promising. This latter method was developed in the 1940s and is increasingly used in a broad range of scientific areas, such as invasion biology, population dynamics, and pest management, with over 400 publications recorded (Naranjo, 2019). In addition, there is a free online protocol for building a standard and affordable flight mill that can record the flight activity of up to 16 insects simultaneously (Attisano et al., 2015). Tests using flight mills might need qualified staff but the recording and analysis can also be done in an automatic manner with sensors and customized scripts. The use of standard flight mills in honeybee toxicological research thus has the potential to provide robust data. However, as for PER conditioning, the ecological relevance of bee activity recorded in indoor conditions remains to be determined. Impairment of locomotion ability, due to alteration of either energetic metabolism (Liao et al., 2019) or brain and muscle excitability (Kadala et al., 2019), may affect the performance of foragers or in-hive bees (like nurse bees). For instance, flight mills have been largely used for better understanding migration in insects, and flight studies have been shown to support field observations (Minter et al., 2018). The challenge though is to define how locomotion patterns obtained in lab- 
controlled conditions can be used to predict honeybee performance in the field and to what extent it could affect colonies.

\subsection{Test endpoints with promising standardisation levels and/or ecological relevance: foraging,} homing flight, queen and drone fertility

The evaluation of pesticide toxicity on foraging activity and homing flights has recently been boosted by the emergence of automatic tracking technologies. The major drawbacks of these bioassays are the cost of equipment and the need for specific technical expertise. However, the toxicity assays are usually performed in more field-realistic conditions than other behavioral endpoints, and both foraging activity and homing flights integrate a wide range of biological functions (learning/memory, orientation, locomotion, energetic metabolism...) with which pesticides with different modes of action may interfere. This may explain why these endpoints are receiving growing interest despite the relative complexity of the measurements. A great majority of these studies have shown consistency in the results obtained (e.g. decrease in the number of visits to the feeder, precocious onset of foraging and mortality, and lowered homing success). It is still difficult to assess the robustness and reproducibility of methods used for recording foraging activity, because studies were mostly performed on different pesticides. However, a dose-dependent effect of sublethal doses of acetamiprid was found on the onset of foraging (Shi et al., 2020), indicating that the recording of foraging activity with tracking technologies is a sensitive method.

Homing flight tests were identified as a useful method to assess the effects of sublethal doses of pesticides on honey bees in field conditions (EFSA, 2013, 2012). The method has been tested since 2015 with a dozen laboratories in different environments (Fourrier et al., 2019). During five years of ring test, the majority of laboratories performed the test successfully. In addition, this method has proved to be sensitive because dose-effect responses have been found (Monchanin et al., 2019). As a whole, the results show that the method is well standardized. The homing flight test, which was proposed to OECD standard protocols for pesticide risk assessment, is currently under evaluation. Even if it has been validated for only thiamethoxam, there is growing evidence for low-dose effects of others insecticides, fungicides and herbicides, on honeybee navigation, foraging activities and flight performances (e.g. 
Balbuena et al., 2015; Bortolotti et al., 2003; Liao et al., 2019; Matsumoto, 2013; Prado et al., 2019;

Vandame et al., 1995). Such endpoints have a high ecological relevance because of the obvious link between the loss of foragers and/or decreased foraging activity and colony development. The rate of forager loss and activity decline that could lead to a critical reduction of the colony size remains an open question. However, population dynamics models might help to fill this gap. For instance, effects on homing failure and foraging performances can be converted into death rate and foraging parameters (resource collection, age at the onset of foraging...), respectively, and implemented into models to investigate the consequences on colony development and survival.

The field of reproductive toxicity in honeybees has been growing recently. Multiple studies are now available that investigated the reproductive toxicity of the same compound and have revealed consistent results. For instance, both Haarmann et al. (2002) and Pettis et al. (2004) showed that exposure to coumaphos during development negatively affects queen weight at emergence. Moreover a series of studies using both Tier 1 (laboratory test) and Tier 2 (semi-field test) approaches to analyze the reproductive toxicity of fipronil found similar results. By first showing that drones reared under laboratory and semi-field conditions had similar semen quality (Ben Abdelkader et al., 2014), they found consistent toxic effects of chronic exposure to fipronil across different times of the year and among years, i.e. higher spermatozoa mortality and lower spermatozoa production (Kairo et al., 2017b, 2017a, 2016). This could serve as a basis for the development of standardized methods for testing the reproductive toxicity of pesticides. If the methods using reproduction as assessment endpoints provide robust results, their sensitivity is less known. Besides Wu-Smart and Spivak (2016) who described a dose-dependent effect of imidacloprid on queen egg-laying rate, most studies tested a single dose or concentration of pesticide. This is likely due to the complex and time-consuming protocols. A clear strength of these reproductive endpoints in pesticide risk assessment is their great ecological relevance: impairment of queen and drone fertility can be readily extrapolated to consequences at the colony level. A decrease in queen egg-laying would generally translate into lower brood production and queen replacement by workers (supersedure) (Hendriksma et al., 2004; Sandrock et al., 2014); the latter being risky for the colony fate if it fails. In addition, smaller queens tend to mate with a lower number of drones and to have a lower sperm count in the spermatheca (Delaney et al., 2011). Reproductive 
endpoints are especially interesting given that the risk associated with poor fertility has been quantified in the literature. For instance, it was found via artificial insemination that a sperm count lower than 4 million results in premature queen supersedures (Harizanis and Gary, 1984; Woyke, 1989c). Additionally, queens that are considered by beekeepers as failing (e.g. poor brood production) or that need to be changed have a lower sperm viability (median value of 55\%) than healthy queens (92\%) (Pettis et al., 2016). Such observations indicate that environmental exposure to fipronil represents a high risk for honeybee colonies. Indeed, Kairo et al. (2016) found that queens inseminated with semen from drones exposed to an environmentally-relevant concentration of fipronil had $62 \%$ sperm viability and 3.14 million spermatozoa on average (vs $75 \%$ sperm viability and 4.62 million spermatozoa for control queens). They would thus fall into the category of failing queens.

\subsection{Relevance of behavioural endpoints from the point of view of stakeholders}

The relevance of some behavioral endpoints within the context of pesticide risk assessment was further evaluated in a participative session of a workshop organized by ITSAP-Institut de l'Abeille and ANSES in January 2020 with different European stakeholders: scientists, beekeeping representatives, regulators, contract laboratory representatives and manufacturers (23 participants). The representatives worked especially on the standardization levels of four behavioral endpoints and associated test methods (PER, waggle dance, foraging activity and homing flight) within the perspective of chemical regulation. The test methods were noted according to the 5 assessment criteria (simplicity, sensitivity, reproducibility, robustness and ecological relevance) (Fig. 2). The test on foraging activity at a syrup feeder scored, on average, the best for all of the criteria. In particular, it was considered easier to implement and more robust than the homing flight test. The homing flight test was well noted for sensitivity, reproducibility of results and the best rated for ecological relevance. The test measuring the effects on social communication (waggle dance) received the lowest score (Fig. 2). While it was not possible to have the variability of the participants' responses, the results of this participative session reflect a reality observed by the participants, namely that there are no behavioral tests that respond perfectly to all of the proposed criteria, and that it is rather a trade-off between the different criteria that must be found. 


\section{Challenges for better integrating behavioral and reproductive performances in}

pesticide risk assessment

\subsection{Translation of toxicological research studies into regulatory test methods}

Research studies performed by academics and testing methods used by governments, industries and independent laboratories generally share the same goal, which is identifying and determining potential hazards of pesticides. However, research studies are often hypothesis-driven or exploratory with relatively complex protocols, as opposed to testing methods that rely on simpler and highly standardized protocols. As a consequence, few research studies share the same methodological designs for the measurement of a given endpoint and the robustness and reproducibility of measurements are difficult to assess. Moving from an exploratory to a standard method therefore requires defining standard measurements (such as the $\mathrm{LD}_{50}$ in mortality tests), sharing full details of protocols, building a broader database and developing comparative studies. A larger number of tested doses/concentrations and replicates will notably help determine whether the method is reliable enough for chemical regulation. Regarding behavioral endpoints, the standardization and analysis of measurements currently benefits from the emergence of new technologies. Labor-intensive and time-consuming recordings of behaviors are now faster and easier thanks to computational tools (e.g. machine learning-based system) and electronic tagging of animals. In addition, such tools contribute to removing or reducing opportunities for human observation error. For instance, optic bee counters and RFID proved to be very efficient in automatically tracking the foraging and homing flights of hundreds of honeybees in toxicological studies. Most importantly they drastically reduced the measurement complexity of these highly ecologically-relevant endpoints, making them more accessible to regulatory test methods. Computer vision algorithms have also been developed to track and phenotype the communication and in-hive behaviors of honeybees. For example, by tracking thousands of bees the BeesBook system allows for the automatic detection and decoding of communication dances (Wario et al., 2015). Similarly, the Bee Behavioral Annotation System (Blut et al., 2017) and the technology developed by Gernat et al. (2018) enable the monitoring of honeybee worker social interactions (trophallaxis, antennation). The next step 
effects on bees, as recently performed by Siefert et al. (2020) for investigating the influence of neonicotinoids on nursing behavior. The improved phenotyping of behaviors that are, by definition, complex, dynamic and noisy will facilitate the potential integration of behavioral endpoints in pesticide risk assessment.

The evaluation of pesticide reproductive toxicity requires the implementation of strong human and technical expertise, both in beekeeping and in the laboratory, which can be limiting for regulatory test methods. Thus, the next step would be to simplify measurement methods. The recent development of cytometry flux methods to determine spermatozoa number and viability in either queen spermatheca or drones has led to more accurate and robust quantification (Pettis et al., 2016; Tofilski et al., 2012; Yániz et al., 2020). Such endpoints notably have the advantage of communicating actual or future queen quality. Identifying in queens and drones the most important route of exposure to pesticides would also help to narrow down tests to the most relevant life stages (larva, adult) and modes of exposure (contact, oral).

\subsection{Improve the extrapolation from effects on individuals to colony response}

To improve the ecological relevance of behavioral and reproductive endpoints, causative links between individual effects and colony response are needed. However, to confidently detect an effect at the colony level, large colony sample size has to be used. This might explain why none of the field studies developed to assess neonicotinoid effects had the power to detect an effect on the size and the fate of the colony based on the EFSA standard (Franklin and Raine, 2019). Efforts are being made to lower variability inherent to semi-field and field methodologies and thus reduce the Minimum Detectable Difference (MDD) (Wang et al., 2020). The use of population dynamics models may help to integrate behavioral and reproductive endpoints into a risk assessment framework. The challenge of scaling up the consequences of adverse behavioral and reproductive effects from individuals to populations (or colonies) as a whole is known as the extrapolation problem (Forbes et al., 2008). Population dynamics models are promising tools in that respect. By population models, Forbes et al. (2008) refer to mechanistic models that relate individual level responses to changes in population size and structure. Such models have been developed for honey bees (Becher et al., 2014; Khoury et al., 2013, 2011; 
Schmickl and Crailsheim, 2007; Torres et al., 2015) and investigated as potential, useful tools to inform pesticide risk assessment because they allow for the joint implementation of mortality endpoints as well as a range of behavioral and reproductive endpoints. To date, most models have been used to assess the consequences of lethal pesticide effects at different individual developmental stages, including eggs, larvae, pupae, in-hive workers and ultimately foragers (e.g. Rumkee et al., 2015; Schmolke et al., 2019). Model users may also tune those mortality parameters, jointly with other sublethal endpoints, to simulate the consequences of pesticide exposure from individual response to risk of colony collapse. Two sublethal parameters may be readily implemented in the context of pesticide risk assessment, namely homing failure and queen egg-laying rate. Homing failure can be readily combined with natural forager death rate to assess its global effect on the colony dynamics (Bryden et al., 2013; Henry et al., 2012). Likewise, reduced egg laying rate is easily introduced into population dynamics models by simply tuning down the daily egg production to simulate impaired queen reproductive activity (Henry et al., 2017; Rumkee et al., 2015). Models are also useful tools to reveal how combined sublethal stresses at the individual scale can act in concert to exacerbate global colony collapse risks (Henry et al., 2017). Still, additional sublethal parameters along with appropriate mathematical response functions need to be formally implemented into population models. Most importantly, their predictive power remains to be thoroughly tested with empirical data.

We do not suggest the use of an in silico approach as a substitute for empirical studies with colony level endpoints, but rather as a tool to narrow down the possible scenarios (e.g. level and duration of exposure) that might lead to the decline of several colony traits, such as brood and adult population size, honey production and colony collapse (Henry et al., 2017). A modelling approach should also give insight into the effect size and time delay before the impact of exposure to pesticide on colony traits. This is particularly important since a pesticide might be considered safe for honeybee colonies if field experiments are not sufficiently well designed, i.e. small-scale experiments and/or short-term monitoring. Therefore, once a risk has been identified at the individual level, population dynamics models may represent a first step screening process to design field experiments able to confidently detect potential changes at the colony level. 


\section{Conclusions}

New endpoints need to be implemented at the screening level of pesticide risk assessment to consider the risk posed by sublethal doses and concentrations in honeybees. We showed here that several behavioral and reproductive endpoints are available thanks to the development of exploratory research studies in ecotoxicology. These endpoints are not all equally standardized and some are simpler than others. However, one of the most important criteria in the decision-making process of risk assessment relies on the ability of the endpoint to communicate information on the potential impact on the population. In this context, homing and reproductive performances have great potential. While measured at the individual level, both provide great insight into the risk at the colony level, since colony

675 demography and dynamics, like for any population, are primarily governed by birth (fecundity) and death (survival) of individuals. However, for using behavioral and reproductive endpoints in pesticide regulation, further work is needed to develop standardized test protocols.

Around 95\% of toxicological studies that used behavioral and reproductive endpoints to investigate the non-target effects of pesticides on honeybees have focused on insecticides (Fig. 1B). This is likely explained by the fact that insecticides are intended to affect insects and generally target the nervous system. In contrast, fungicides and herbicides are usually not considered as a threat to honeybees due to their high $\mathrm{LD}_{50}$ values (Zioga et al., 2020). However, there is now growing evidence for lethal and sublethal effects induced by such pesticides (Cullen et al., 2019). Notably, fungicides may affect honeybee energetic metabolism (Degrandi-Hoffman et al., 2015), which can translate into impaired behavioral performance (Liao et al., 2019; Prado et al., 2019). In addition, in terms of tonnage, insecticide use is outweighed by fungicides and herbicides (Cullen et al., 2019). There is thus a clear need for filling the gap on the evaluation of fungicide and herbicide toxicity. In this context, behavioral and reproductive endpoints are of great interest, especially given that field-realistic exposures to fungicides and herbicides are generally below their $\mathrm{LD}_{50}$ values (Ostiguy et al., 2019; Prado et al., 2019). Future research on fungicides and herbicides will notably have to screen a range of endpoints and investigate which ones are the most appropriate for use in regulatory risk assessment, as they might differ between pesticide type and family. 


\section{Acknowledgments}

This project received funding from the European Horizon 2020 research and innovation programme under grant agreement no. 773921 (LB, YLC and CA).

\section{References}

Abramson, C.I., Sokolowski, M.B.C., Brown, E.A., Pilard, S., 2012. The effect of pymetrozine (Plenum WG-50®) on proboscis extension conditioning in honey bees (Apis mellifera: Hybrid var. Buckfast). Ecotoxicol. Environ. Saf. 78, 287-295. https://doi.org/10.1016/j.ecoenv.2011.11.038

Abramson, C.I., Squire, J., Sheridan, A., Mulder, P.G., 2004. The effect of insecticides considered harmless to honey bees (Apis mellifera): proboscis conditioning studies by using the insect growth regulators tebufenozide and diflubenzuron. Environ. Entomol. 33, 378-388. https://doi.org/10.1603/0046-225X-33.2.378

Ågerstrand, M., Arnold, K., Balshine, S., Brodin, T., Brooks, B.W., Maack, G., McCallum, E.S., Pyle, G., Saaristo, M., Ford, A.T., 2020. Emerging investigator series: use of behavioural endpoints in the regulation of chemicals. Environ. Sci.: Processes Impacts 22, 49-65. https://doi.org/10.1039/C9EM00463G

710 Aliouane, Y., el Hassani, A.K., Gary, V., Armengaud, C., Lambin, M., Gauthier, M., 2009. Subchronic exposure of honeybees to sublethal doses of pesticides: effects on behavior. Environ. Toxicol. Chem. 28, 113. https://doi.org/10.1897/08-110.1

Alkassab, A.T., Kirchner, W.H., 2017. Sublethal exposure to neonicotinoids and related side effects on insect pollinators: honeybees, bumblebees, and solitary bees. J. Plant Dis. Prot. 124, 1-30. https://doi.org/10.1007/s41348-016-0041-0

Armengaud, C., Lambin, M., Gauthier, M., 2002. Effects of imidacloprid on the neuralprocesses of memory in honey bees., in: Honey Bees: Estimating the Environmental Impact of Chemicals. London/New York: Taylor \& Francis, pp. 85-100.

Attisano, A., Murphy, J.T., Vickers, A., Moore, P.J., 2015. A Simple Flight Mill for the Study of Tethered Flight in Insects. JoVE e53377. https://doi.org/10.3791/53377

Aufauvre, J., Misme-Aucouturier, B., Viguès, B., Texier, C., Delbac, F., Blot, N., 2014. Transcriptome analyses of the honeybee response to Nosema ceranae and insecticides. PLoS ONE 9, e91686. https://doi.org/10.1371/journal.pone.0091686

Balbuena, M.S., Tison, L., Hahn, M.-L., Greggers, U., Menzel, R., Farina, W.M., 2015. Effects of sublethal doses of glyphosate on honeybee navigation. J. Exp. Biol. 218, 2799-2805. https://doi.org/10.1242/jeb.117291

Becher, M.A., Grimm, V., Thorbek, P., Horn, J., Kennedy, P.J., Osborne, J.L., 2014. BEEHAVE: a systems model of honeybee colony dynamics and foraging to explore multifactorial causes of colony failure. J. Appl. Ecol. 51, 470-482. https://doi.org/10.1111/1365-2664.12222

Beekman, M., Ratnieks, F.L.W., 2000. Long-range foraging by the honey-bee, Apis mellifera L. Funct. Ecology 14, 490-496. https://doi.org/10.1046/j.1365-2435.2000.00443.x

Belzunces, L.P., Tchamitchian, S., Brunet, J.-L., 2012. Neural effects of insecticides in the honey bee. Apidologie 43, 348-370. https://doi.org/10.1007/s13592-012-0134-0

Ben Abdelkader, F., Kairo, G., Tchamitchian, S., Cousin, M., Senechal, J., Crauser, D., Vermandere, J.P., Alaux, C., Le Conte, Y., Belzunces, L.P., Barbouche, N., Brunet, J.-L., 2014. Semen quality of honey bee drones maintained from emergence to sexual maturity under laboratory, semi-field and field conditions. Apidologie 45, 215-223. https://doi.org/10.1007/s13592-0130240-7

Bendahou, N., Fleche, C., Bounias, M., 1999. Biological and biochemical effects of chronic exposure to very low levels of dietary cypermethrin (Cymbush) on honeybee colonies (Hymenoptera: Apidae). Ecotoxicol. Environ. Saf. 44, 147-153. https://doi.org/10.1006/eesa.1999.1812 
Blacquière, T., Smagghe, G., van Gestel, C.A.M., Mommaerts, V., 2012. Neonicotinoids in bees: a review on concentrations, side-effects and risk assessment. Ecotoxicology 21, 973-992. https://doi.org/10.1007/s10646-012-0863-x

Blut, C., Crespi, A., Mersch, D., Keller, L., Zhao, L., Kollmann, M., Schellscheidt, B., Fülber, C., Beye, M., 2017. Automated computer-based detection of encounter behaviours in groups of honeybees. Sci Rep 7, 17663. https://doi.org/10.1038/s41598-017-17863-4

Böhme, F., Bischoff, G., Zebitz, C.P.W., Rosenkranz, P., Wallner, K., 2018. From field to food-will pesticide-contaminated pollen diet lead to a contamination of royal jelly? Apidologie 49, 112119. https://doi.org/10.1007/s13592-017-0533-3

Bordier, C., Klein, S., Le Conte, Y., Barron, A.B., Alaux, C., 2018. Stress decreases pollen foraging performance in honeybees. J. Exp. Biol. 221, jeb171470. https://doi.org/10.1242/jeb.171470

Bortolotti, L., Montanari, R., Marcelino, J., Medrzycki, P., Maini, S., Porrini, C., 2003. Effects of sublethal imidacloprid doses on the homing rate and foraging activity of honey bees. Bull. Insectology 56, 63-67.

Bryden, J., Gill, R.J., Mitton, R.A.A., Raine, N.E., Jansen, V.A.A., 2013. Chronic sublethal stress causes bee colony failure. Ecol. Lett. 16, 1463-1469. https://doi.org/10.1111/ele.12188

Büchler, R., Andonov, S., Bienefeld, K., Costa, C., Hatjina, F., Kezic, N., Kryger, P., Spivak, M., Uzunov, A., Wilde, J., 2013. Standard methods for rearing and selection of Apis mellifera queens. Journal of Apicultural Research 52, 1-30. https://doi.org/10.3896/IBRA.1.52.1.07

Cabirol, A., Cope, A.J., Barron, A.B., Devaud, J.-M., 2018. Relationship between brain plasticity, learning and foraging performance in honey bees. PLoS ONE 13, e0196749. https://doi.org/10.1371/journal.pone.0196749

Carson, 1962. Silent spring., Houghton Mifflin Company, Boston, Mass., USA.

Charreton, M., Decourtye, A., Henry, M., Rodet, G., Sandoz, J.-C., Charnet, P., Collet, C., 2015. A locomotor deficit induced by sublethal doses of pyrethroid and neonicotinoid insecticides in the honeybee Apis mellifera. PLoS ONE 10, e0144879. https://doi.org/10.1371/journal.pone.0144879

Chauzat, M.-P., Faucon, J.-P., 2007. Pesticide residues in beeswax samples collected from honey bee colonies (Apis mellifera L.) in France. Pest. Manag. Sci. 63, 1100-1106. https://doi.org/10.1002/ps.1451

Ciereszko, A., Wilde, J., Dietrich, G.J., Siuda, M., Bąk, B., Judycka, S., Karol, H., 2017. Sperm parameters of honeybee drones exposed to imidacloprid. Apidologie 48, 211-222. https://doi.org/10.1007/s13592-016-0466-2

Colin, T., Meikle, W.G., Paten, A.M., Barron, A.B., 2019a. Long-term dynamics of honey bee colonies following exposure to chemical stress. Science of The Total Environment 677, 660-670. https://doi.org/10.1016/j.scitotenv.2019.04.402

Colin, T., Meikle, W.G., Wu, X., Barron, A.B., 2019b. Traces of a neonicotinoid induce precocious foraging and reduce foraging performance in honey bees. Environ. Sci. Technol. 53, 82528261. https://doi.org/10.1021/acs.est.9b02452

Cox, R.L., Wilson, W.T., 1984. Effects of permethrin on the behavior of individually tagged honey bees, Apis mellifera L. (hymenoptera: apidae). Environ. Entomol. 13, 375-378. https://doi.org/10.1093/ee/13.2.375

Cullen, M.G., Thompson, L.J., Carolan, James.C., Stout, J.C., Stanley, D.A., 2019. Fungicides, herbicides and bees: A systematic review of existing research and methods. PLoS ONE 14, e0225743. https://doi.org/10.1371/journal.pone.0225743

Dai, P.-L., Wang, Q., Sun, J.-H., Liu, F., Wang, X., Wu, Y.-Y., Zhou, T., 2010. Effects of sublethal concentrations of bifenthrin and deltamethrin on fecundity, growth, and development of the honeybee Apis mellifera ligustica. Environ. Toxicol. Chem. 29, 644-649. https://doi.org/10.1002/etc.67

de Mattos, I.M., Soares, A.E.E., Tarpy, D.R., 2017. Effects of synthetic acaricides on honey bee grooming behavior against the parasitic Varroa destructor mite. Apidologie 48, 483-494. https://doi.org/10.1007/s13592-017-0491-9

Decourtye, A., Armengaud, C., Renou, M., Devillers, J., Cluzeau, S., Gauthier, M., Pham-Delègue, M.H., 2004a. Imidacloprid impairs memory and brain metabolism in the honeybee (Apis mellifera L.). Pestic. Biochem. Physiol. 78, 83-92. https://doi.org/10.1016/j.pestbp.2003.10.001 
Decourtye, A., Devillers, J., Aupinel, P., Brun, F., Bagnis, C., Fourrier, J., Gauthier, M., 2011. Honeybee tracking with microchips: a new methodology to measure the effects of pesticides. Ecotoxicology 20, 429-437. https://doi.org/10.1007/s10646-011-0594-4

Decourtye, A., Devillers, J., Cluzeau, S., Charreton, M., Pham-Delègue, M.-H., 2004b. Effects of imidacloprid and deltamethrin on associative learning in honeybees under semi-field and laboratory conditions. Ecotoxicol. Environ. Saf. 57, 410-419. https://doi.org/10.1016/j.ecoenv.2003.08.001

Decourtye, A., Lacassie, E., Pham-Delègue, M.-H., 2003. Learning performances of honeybees (Apis mellifera L) are differentially affected by imidacloprid according to the season: Effects of imidacloprid on learning performances of honeybees. Pest. Manag. Sci. 59, 269-278. https://doi.org/10.1002/ps.631

Decourtye, A., Lefort, S., Devillers, J., Gauthier, M., Aupinel, P., Tisseur, M., 2009. Sublethal effects of fipronil on the ability of honeybees (Apis mellifera L.) to orientate in a complex maze. Presented at the 10th International Symposium of the ICP-BR Bee Protection Group, Hazards of pesticides to bees, Bucarest, p. 9.

Decourtye, A., Pham-Delègue, M.H., 2002. Assessing the sublethal effects of pesticides on the honey bee, in: Honey Bees: Estimating the Environmental Impact of Chemicals, CRC Press. pp. 6784.

Degrandi-Hoffman, G., Chen, Y., Watkins Dejong, E., Chambers, M.L., Hidalgo, G., 2015. Effects of oral exposure to fungicides on honey bee nutrition and virus levels. J. Econ. Entomol. 108, 2518-2528. https://doi.org/10.1093/jee/tov251

Delaney, D.A., Keller, J.J., Caren, J.R., Tarpy, D.R., 2011. The physical, insemination, and reproductive quality of honey bee queens (Apis mellifera L.). Apidologie 42, 1-13. https://doi.org/10.1051/apido/2010027

Delkash-Roudsari, S., Chicas-Mosier, A.M., Goldansaz, S.H., Talebi-Jahromi, K., Ashouri, A., Abramson, C.I., 2020. Assessment of lethal and sublethal effects of imidacloprid, ethion, and glyphosate on aversive conditioning, motility, and lifespan in honey bees (Apis mellifera L.). Ecotoxicol. Environ. Saf. 204, 111108. https://doi.org/10.1016/j.ecoenv.2020.111108

Desneux, N., Decourtye, A., Delpuech, J.-M., 2007. The sublethal effects of pesticides on beneficial arthropods. Annu. $\quad$ Rev. Entomol. 52, 81-106. https://doi.org/10.1146/annurev.ento.52.110405.091440

Di Prisco, G., Cavaliere, V., Annoscia, D., Varricchio, P., Caprio, E., Nazzi, F., Gargiulo, G., Pennacchio, F., 2013. Neonicotinoid clothianidin adversely affects insect immunity and promotes replication of a viral pathogen in honey bees. Proc. Natl. Acad. Sci. 110, 1846618471. https://doi.org/10.1073/pnas.1314923110

Donaldson-Matasci, M.C., Dornhaus, A., 2012. How habitat affects the benefits of communication in collectively foraging honey bees. Behav. Ecol. Sociobiol. 66, 583-592. https://doi.org/10.1007/s00265-011-1306-z

835 Dornhaus, A., Chittka, L., 2004. Why do honey bees dance? Behav. Ecol. Sociobiol. 55, 395-401. https://doi.org/10.1007/s00265-003-0726-9

Dudley, R., 2000. The Biomechanics of insect flight: From, Function, Evolution. PRINCETON, NEW JERSEY: Princeton University Press.

Durant, J.L., 2020. Ignorance loops: how non-knowledge about bee-toxic agrochemicals is iteratively produced. Soc. Stud. Sci. 1-27. https://doi.org/10.1177/0306312720923390

Dyer, F.C., 2002. The biology of the dance language. Annu. Rev. Entomol. 47, 917-949. https://doi.org/10.1146/annurev.ento.47.091201.145306

Dyer, F.C., Gould, J.L., 1981. Honey bee orientation: a backup system for cloudy days. Science 214, 1041-1042. https://doi.org/10.1126/science.214.4524.1041

EFSA, 2013. EFSA Guidance Document on the risk assessment of plant protection products on bees (Apis mellifera, Bombus spp. and solitary bees). EFSA Journal 11(7), 268 pp.

EFSA, 2012. Scientific Opinion on the science behind the development of a risk assessment of Plant Protection Products on bees (Apis mellifera, Bombus spp. and solitary bees). EFSA Journal 10(5), 275 pp. 
Eiri, D.M., Nieh, J.C., 2012. A nicotinic acetylcholine receptor agonist affects honey bee sucrose responsiveness and decreases waggle dancing. J Exp Biol 215, 2022-2029. https://doi.org/10.1242/jeb.068718

El Hassani, A.K., Dacher, M., Gary, V., Lambin, M., Gauthier, M., Armengaud, C., 2008. Effects of sublethal doses of acetamiprid and thiamethoxam on the behavior of the honeybee (Apis mellifera). Arch. Environ. Contam. Toxicol. 54, 653-661. https://doi.org/10.1007/s00244-0079071-8

El Hassani, A.K., Dacher, M., Gauthier, M., Armengaud, C., 2005. Effects of sublethal doses of fipronil on the behavior of the honeybee (Apis mellifera). Pharmacol. Biochem. Behav. 82, 30-39. https://doi.org/10.1016/j.pbb.2005.07.008

EPPO, 2010a. EPPO Standards PP 3/10 (3) Environmental risk assessment scheme for plant protection products, Chapter 10: Honeybees. Bulletin 40, 323-331.

EPPO, 2010b. EPPO standards PP 1/170 (4) Efficacy evaluation of plant protection products. Sideeffects on honeybees. Bulletin 40, 313-319.

Evans, J.D., Spivak, M., 2010. Socialized medicine: Individual and communal disease barriers in honey bees. J. Invertebr. Pathol. 103, S62-S72. https://doi.org/10.1016/j.jip.2009.06.019

Evans, L.J., Smith, K.E., Raine, N.E., 2017. Fast learning in free-foraging bumble bees is negatively correlated with lifetime resource collection. Sci. Rep. 7, 496. https://doi.org/10.1038/s41598017-00389-0

Feltham, H., Park, K., Goulson, D., 2014. Field realistic doses of pesticide imidacloprid reduce bumblebee pollen foraging efficiency. Ecotoxicology 23, 317-323. https://doi.org/10.1007/s10646-014-1189-7

Fischer, J., Müller, T., Spatz, A.-K., Greggers, U., Grünewald, B., Menzel, R., 2014. Neonicotinoids interfere with specific components of navigation in honeybees. PLoS ONE 9, e91364. https://doi.org/10.1371/journal.pone.0091364

875 Fisher, A., Rangel, J., 2018. Exposure to pesticides during development negatively affects honey bee (Apis mellifera) drone sperm viability. PLoS ONE 13, e0208630. https://doi.org/10.1371/journal.pone.0208630

Forbes, V.E., Calow, P., Sibly, R.M., 2008. The extrapolation problem and how population modeling can help. Environ. Toxicol. Chem. 27(10), 1987-1994. https://doi.org/10.1897/08-029.1

Fourrier, J., Moreau-Vauzelle, C., Chevallereau, C., Aupinel, P., Henry, M., Vidau, C., Decourtye, A., 2019. The homing flight method to assess the effect of sublethal doses of plant protection products on the honey bee in field conditions: results of the ring tests and proposal of an OECD TG. Presented at the ICPPR, 14th international symposium, Hazards of pesticides to bees, Bern.

Franklin, E.L., Raine, N.E., 2019. Moving beyond honeybee-centric pesticide risk assessments to protect all pollinators. Nat. Ecol. Evol. 3, 1373-1375. https://doi.org/10.1038/s41559-019-0987-y

Gernat, T., Rao, V.D., Middendorf, M., Dankowicz, H., Goldenfeld, N., Robinson, G.E., 2018. Automated monitoring of behavior reveals bursty interaction patterns and rapid spreading dynamics in honeybee social networks. Proc. Natl. Acad. Sci. 115, 1433-1438. https://doi.org/10.1073/pnas.1713568115

890 Ghazoul, J., 2005. Buzziness as usual? Questioning the global pollination crisis. Trends Ecol. Evol. 20, 367-373. https://doi.org/10.1016/j.tree.2005.04.026

Gill, R.J., Ramos-Rodriguez, O., Raine, N.E., 2012. Combined pesticide exposure severely affects individual- and colony-level traits in bees. Nature 491, 105-108. https://doi.org/10.1038/nature11585

Giurfa, M., Sandoz, J.-C., 2012. Invertebrate learning and memory: fifty years of olfactory conditioning of the proboscis extension response in honeybees. Learn. Mem. 19, 54-66. https://doi.org/10.1101/lm.024711.111

Greggers, U., Koch, G., Schmidt, V., Dürr, A., Floriou-Servou, A., Piepenbrock, D., Göpfert, M.C., Menzel, R., 2013. Reception and learning of electric fields in bees. Proc. R. Soc. B 280, 20130528. https://doi.org/10.1098/rspb.2013.0528

Grozinger, C.M., Flenniken, M.L., 2019. Bee viruses: Eecology, pathogenicity, and impacts. Annu. Rev. Entomol. 64, 205-226. https://doi.org/10.1146/annurev-ento-011118-111942 
Guez, D., Suchail, S., Gauthier, M., Maleszka, R., Belzunces, L.P., 2001. Contrasting effects of imidacloprid on habituation in 7- and 8-day-old honeybees (Apis mellifera). Neurobiol. Learn. Mem. 76, 183-191. https://doi.org/10.1006/nlme.2000.3995

Guez, D., Zhang, S.-W., Srinivasan, M.V., 2005. Methyl parathion modifies foraging behaviour in honeybees (Apis mellifera). Ecotoxicology 14, 431-437. https://doi.org/10.1007/s10646-0041348-3

Haarmann, T., Spivak, M., Weaver, D., Weaver, B., Glenn, T., 2002. Effects of fluvalinate and coumaphos on queen honey bees (Hymenoptera: Apidae) in two commercial queen rearing operations. J. Econ. Entomol. 95, 28-35. https://doi.org/10.1603/0022-0493-95.1.28

Harizanis, P.C., Gary, N.E., 1984. The quality of insemination of queen honey bees mated under commercial conditions. Am. Bee J. 124, 385-387.

Hendriksma, H.P., Callis, J.N.M., Boot, W.J., 2004. Stimulating nautral supersedure of honeybee queens, Apis mellifera. Proc. Neth. Soc. Entomol. 15, 29-33.

Henry, M., Becher, M.A., Osborne, J.L., Kennedy, P.J., Aupinel, P., Bretagnolle, V., Brun, F., Grimm, V., Horn, J., Requier, F., 2017. Predictive systems models can help elucidate bee declines driven by multiple combined stressors. Apidologie 48, 328-339. https://doi.org/10.1007/s13592-0160476-0

Henry, M., Beguin, M., Requier, F., Rollin, O., Odoux, J.-F., Aupinel, P., Aptel, J., Tchamitchian, S., Decourtye, A., 2012. A common pesticide decreases foraging success and survival in honey bees. Science 336, 348-350. https://doi.org/10.1126/science.1215039

Henry, M., Bertrand, C., Le Féon, V., Requier, F., Odoux, J.-F., Aupinel, P., Bretagnolle, V., Decourtye, A., 2014. Pesticide risk assessment in free-ranging bees is weather and landscape dependent. Nat. Commun. 5, 4359. https://doi.org/10.1038/ncomms5359

Henry, M., Cerrutti, N., Aupinel, P., Decourtye, A., Gayrard, M., Odoux, J.-F., Pissard, A., Rüger, C., Bretagnolle, V., 2015. Reconciling laboratory and field assessments of neonicotinoid toxicity to honeybees. Proc. R. Soc. B. 282, 20152110. https://doi.org/10.1098/rspb.2015.2110

Hesselbach, H., Scheiner, R., 2018. Effects of the novel pesticide flupyradifurone (Sivanto) on honeybee taste and cognition. Sci. Rep. 8, 4954. https://doi.org/10.1038/s41598-018-23200-0

Hesselbach, H., Seeger, J., Schilcher, F., Ankenbrand, M., Scheiner, R., 2020. Chronic exposure to the pesticide flupyradifurone can lead to premature onset of foraging in honeybees Apis mellifera. J. Appl. Ecol. 57(3), 609-618. https://doi.org/10.1111/1365-2664.13555

Hirata, K., 2016. Studies on the mode of action of neurotoxic insecticides. J. Pest. Sci. 41, 87-94. https://doi.org/10.1584/jpestics.J16-01

Ingram, E.M., Augustin, J., Ellis, M.D., Siegfried, B.D., 2015. Evaluating sub-lethal effects of orchardapplied pyrethroids using video-tracking software to quantify honey bee behaviors. Chemosphere 135, 272-277. https://doi.org/10.1016/j.chemosphere.2015.04.022

Johnson, R.M., 2015. Honey bee toxicology. Annu. Rev. Entomol. 60, 415-434. https://doi.org/10.1146/annurev-ento-011613-162005

Kadala, A., Charreton, M., Charnet, P., Collet, C., 2019. Honey bees long-lasting locomotor deficits after exposure to the diamide chlorantraniliprole are accompanied by brain and muscular calcium channels alterations. Sci. Rep. 9, 2153. https://doi.org/10.1038/s41598-019-39193-3

Kairo, G., Biron, D.G., Ben Abdelkader, F., Bonnet, M., Tchamitchian, S., Cousin, M., Dussaubat, C., Benoit, B., Kretzschmar, A., Belzunces, L.P., Brunet, J.-L., 2017a. Nosema ceranae, fipronil and their combination compromise honey bee reproduction via changes in male physiology. Sci. Rep. 7, 8556. https://doi.org/10.1038/s41598-017-08380-5

Kairo, G., Poquet, Y., Haji, H., Tchamitchian, S., Cousin, M., Bonnet, M., Pelissier, M., Kretzschmar, A., Belzunces, L.P., Brunet, J.-L., 2017b. Assessment of the toxic effect of pesticides on honey bee drone fertility using laboratory and semifield approaches: A case study of fipronil: Assessment of pesticide reprotoxicity in the honey bee. Environ. Toxicol. Chem. 36, 23452351. https://doi.org/10.1002/etc.3773

Kairo, G., Provost, B., Tchamitchian, S., Ben Abdelkader, F., Bonnet, M., Cousin, M., Sénéchal, J., Benet, P., Kretzschmar, A., Belzunces, L.P., Brunet, J.-L., 2016. Drone exposure to the systemic insecticide fipronil indirectly impairs queen reproductive potential. Sci. Rep. 6, 31904. https://doi.org/10.1038/srep31904 
Karahan, A., Çakmak, I., Hranitz, J.M., Karaca, I., Wells, H., 2015. Sublethal imidacloprid effects on honey bee flower choices when foraging. Ecotoxicology 24, 2017-2025. https://doi.org/10.1007/s10646-015-1537-2

Kays, R., Crofoot, M.C., Jetz, W., Wikelski, M., 2015. Terrestrial animal tracking as an eye on life and planet. Science 348. https://doi.org/10.1126/science.aaa2478

Khoury, D.S., Barron, A.B., Myerscough, M.R., 2013. Modelling food and population dynamics in honey bee colonies. PLoS ONE 8, e59084. https://doi.org/10.1371/journal.pone.0059084

Khoury, D.S., Myerscough, M.R., Barron, A.B., 2011. A quantitative model of honey bee colony population dynamics. PLoS ONE 6, e18491. https://doi.org/10.1371/journal.pone.0018491

Kirchner, W.H., 1999. 17. Mad-Bee-Disease? Subletale Effekte von Imidacloprid (Gaucho®) auf das Verhalten von Honigbienen. Apidologie, Springer Verlag 30, 421-422.

Klein, A.-M., Vaissière, B.E., Cane, J.H., Steffan-Dewenter, I., Cunningham, S.A., Kremen, C., Tscharntke, T., 2007. Importance of pollinators in changing landscapes for world crops. Proc. R. Soc. B. 274, 303-313. https://doi.org/10.1098/rspb.2006.3721

Lach, L., Kratz, M., Baer, B., 2015. Parasitized honey bees are less likely to forage and carry less pollen. Journal of Invertebrate Pathology 130, 64-71. https://doi.org/10.1016/j.jip.2015.06.003

Lambin, M., Armengaud, C., Raymond, S., Gauthier, M., 2001. Imidacloprid-induced facilitation of the Proboscis Extension Reflex habituation in the honeybee. Arch. Insect Biochem. Physiol. 129134. https://doi.org/10.1002/arch.1065

Liao, L.-H., Wu, W.-Y., Dad, A., Berenbaum, M.R., 2019. Fungicide suppression of flight performance in the honeybee (Apis mellifera) and its amelioration by quercetin. Proc. R. Soc. B. 286, 20192041. https://doi.org/10.1098/rspb.2019.2041

Matsumoto, T., 2013. Reduction in homing flights in the honey bee Apis mellifera after a sublethal dose of neonicotinoid insecticides. Bull. Insectology 66, 1-9.

Meikle, W.G., Adamczyk, J.J., Weiss, M., Gregorc, A., Johnson, D.R., Stewart, S.D., Zawislak, J., Carroll, M.J., Lorenz, G.M., 2016. Sublethal effects of imidacloprid on honey bee colony growth and activity at three sites in the U.S. PLoS ONE 11, e0168603. https://doi.org/10.1371/journal.pone.0168603

Menzel, R., 1999. Memory dynamics in the honeybee. J. Comp. Physiol. A. 185, 323-340. https://doi.org/10.1007/s003590050392

Menzel, R., Müller, U., 1996. Learning and memory in honeybees: from behavior to neural substrates. Annu. Rev. Neurosci. 19, 379-404.

Minter, M., Pearson, A., Lim, K.S., Wilson, K., Chapman, J.W., Jones, C.M., 2018. The tethered flight technique as a tool for studying life-history strategies associated with migration in insects: Tethered flight for studying insect movement. Ecol. Entomol. 43, 397-411. https://doi.org/10.1111/een.12521

Monchanin, C., Henry, M., Decourtye, A., Dalmon, A., Fortini, D., Bœuf, E., Dubuisson, L., Aupinel, P., Chevallereau, C., Petit, J., Fourrier, J., 2019. Hazard of a neonicotinoid insecticide on the homing flight of the honeybee depends on climatic conditions and Varroa infestation. Chemosphere 224, 360-368. https://doi.org/10.1016/j.chemosphere.2019.02.129

Morand-Ferron, J., Cole, E.F., Quinn, J.L., 2016. Studying the evolutionary ecology of cognition in the wild: a review of practical and conceptual challenges: Evolutionary ecology of cognition in the wild. Biol. Rev. 91, 367-389. https://doi.org/10.1111/brv.12174

Morfin, N., Goodwin, P.H., Correa-Benitez, A., Guzman-Novoa, E., 2019. Sublethal exposure to clothianidin during the larval stage causes long-term impairment of hygienic and foraging behaviour of honey bees. Apidologie 50, 595-605. https://doi.org/10.1007/s13592-019-006721

Mullin, C.A., Frazier, M., Frazier, J.L., Ashcraft, S., Simonds, R., vanEngelsdorp, D., Pettis, J.S., 2010. High levels of miticides and agrochemicals in north american apiaries: implications for honey bee health. PLoS ONE 5, e9754. https://doi.org/10.1371/journal.pone.0009754

Muth, F., Leonard, A.S., 2019. A neonicotinoid pesticide impairs foraging, but not learning, in freeflying bumblebees. Sci. Rep. 9, 4764. https://doi.org/10.1038/s41598-019-39701-5

Naranjo, S.E., 2019. Assessing insect flight behavior in the laboratory: a primer on flight mill methodology and what can be learned. Ann. Entomol. Soc. Am. 112, 182-199. https://doi.org/10.1093/aesa/say041 
Odemer, R., Rosenkranz, P., 2020. Chronic exposure to a neonicotinoid pesticide and a synthetic pyrethroid in full-sized honey bee colonies. J. Apic. Res. 59, 2-11. https://doi.org/10.1080/00218839.2019.1675337

1015

OECD, 2017. Test No. 245: honey bee (Apis mellifera L.), chronic oral toxicity test (10-day feeding), OECD. ed, OECD Guidelines for the Testing of Chemicals, Section 2,. Paris. https://doi.org/10.1787/9789264284098-fr

OECD, 2013. Test No. 237: honey bee (Apis mellifera) larval toxicity test, single exposure, OECD. ed, OECD Guidelines for the Testing of Chemicals, Section 2. Paris. https://doi.org/10.1787/9789264203754-fr

OECD, 2005. Guidance document on the validation and international acceptance of new or updated test methods for hazard assessment. OECD series on testing and assessment, Number 34. ENV/JM/MONO(2005)14. Environment Directorate, Paris: Organisation for Economic Cooperation and Development, Paris. 96 p.

1025 OECD, 1998a. Test No. 213: Honeybees, acute oral toxicity test, OECD. ed, OECD Guidelines for the Testing of Chemicals, Section 2. Paris. https://doi.org/10.1787/9789264070172-fr

OECD, 1998b. Test No. 214: honeybees, acute contact toxicity test, OECD. ed, OECDGuidelines for the Testing of Chemicals, Section 2. Paris. https://doi.org/10.1787/9789264070196-fr

1030

Oliver, C.J., Softley, S., Williamson, S.M., Stevenson, P.C., Wright, G.A., 2015. Pyrethroids and nectar toxins have subtle effects on the motor function, grooming and wing fanning behaviour of honeybees (Apis mellifera). PLoS ONE 10, e0133733. https://doi.org/10.1371/journal.pone.0133733

Ostiguy, N., Drummond, F.A., Aronstein, K., Eitzer, B., Ellis, J.D., Spivak, M., Sheppard, W.S., 2019. Honey bee exposure to pesticides: a four-year nationwide study. Insects 10, 13. https://doi.org/10.3390/insects 10010013

1035

Pahl, M., Zhu, H., Tautz, J., Zhang, S., 2011. Large ccale homing in honeybees. PLoS ONE 6, e19669. https://doi.org/10.1371/journal.pone.0019669

Papach, A., Fortini, D., Grateau, S., Aupinel, P., Richard, F.-J., 2017. Larval exposure to thiamethoxam and American foulbrood: effects on mortality and cognition in the honey bee Apis mellifera. J. Apic. Res. 56, 475-486. https://doi.org/10.1080/00218839.2017.1332541

Pettis, J.S., Collins, A.M., Wilbanks, Reg., Feldlaufer, Mark.F., 2004. Effects of coumaphos on queen rearing in the honey bee, Apis mellifera. Apidologie 35, 605-610. https://doi.org/10.1051/apido:2004056

1045

Pettis, J.S., Rice, N., Joselow, K., vanEngelsdorp, D., Chaimanee, V., 2016. Colony Failure Linked to Low Sperm Viability in Honey Bee (Apis mellifera) Queens and an Exploration of Potential Causative Factors. PLoS ONE 11, e0147220. https://doi.org/10.1371/journal.pone.0147220

Pettis, J.S., Wilson, W.T., Shimanuki, H., Teel, P.D., 1991. Fluvalinate treatment of queen and worker honey bees (Apis mellifera L) and effects on subsequent mortality, queen acceptance and supersedure. Apidologie 22, 1-7. https://doi.org/10.1051/apido:19910101

1050 Poquet, Y., Vidau, C., Alaux, C., 2016. Modulation of pesticide response in honeybees. Apidologie 47, 412-426. https://doi.org/10.1007/s13592-016-0429-7

Prado, A., Pioz, M., Vidau, C., Requier, F., Jury, M., Crauser, D., Brunet, J.-L., Le Conte, Y., Alaux, C., 2019. Exposure to pollen-bound pesticide mixtures induces longer-lived but less efficient honey bees. Sci. Total Environ. 650, 1250-1260. https://doi.org/10.1016/j.scitotenv.2018.09.102

Ramirez-Romero, R., Chaufaux, J., Pham-Delègue, M.-H., 2005. Effects of Cry1Ab protoxin, deltamethrin and imidacloprid on the foraging activity and the learning performancesof the honeybee Apis mellifera, a comparative approach. Apidologie 36, 601-611. https://doi.org/10.1051/apido:2005039

1060

Rangel, J., Keller, J.J., Tarpy, D.R., 2013. The effects of honey bee (Apis mellifera L.) queen reproductive potential on colony growth. Insect. Soc. 60, 65-73. https://doi.org/10.1007/s00040-012-0267-1

Rasmussen, J.J., Wiberg-Larsen, P., Baattrup-Pedersen, A., Friberg, N., Kronvang, B., 2012. Stream habitat structure influences macroinvertebrate response to pesticides. Environ. Pollut. 164, 142 149. https://doi.org/10.1016/j.envpol.2012.01.007 
Retschnig, G., Williams, G.R., Odemer, R., Boltin, J., Di Poto, C., Mehmann, M.M., Retschnig, P., Winiger, P., Rosenkranz, P., Neumann, P., 2015. Effects, but no interactions, of ubiquitous pesticide and parasite stressors on honey bee (Apis mellifera) lifespan and behaviour in a colony environment: Stressor effects in honey bee colonies. Environ. Microbiol. 17, 4322-4331. https://doi.org/10.1111/1462-2920.12825

Rudén, C., Adams, J., Ågerstrand, M., Brock, T.C., Poulsen, V., Schlekat, C.E., Wheeler, J.R., Henry, T.R., 2017. Assessing the relevance of ecotoxicological studies for regulatory decision making: eelevance assessment of ecotoxicological studies. Integr. Environ. Assess. Manag. 13, 652-663. https://doi.org/10.1002/ieam.1846

1075

1080

1085

1090

1095

1100

1105

1110

1115

Rumkee, J.C.O., Becher, M.A., Thorbek, P., Kennedy, P.J., Osborne, J.L., 2015. Predicting Honeybee Colony Failure: Using the BEEHAVE Model to Simulate Colony Responses to Pesticides. Environ. Sci. Technol. 49, 12879-12887. https://doi.org/10.1021/acs.est.5b03593

Sandrock, C., Tanadini, M., Tanadini, L.G., Fauser-Misslin, A., Potts, S.G., Neumann, P., 2014. Impact of Chronic Neonicotinoid Exposure on Honeybee Colony Performance and Queen Supersedure. PLoS ONE 9, e103592. https://doi.org/10.1371/journal.pone.0103592

Santos, A.C.C., Cristaldo, P.F., Araújo, A.P.A., Melo, C.R., Lima, A.P.S., Santana, E.D.R., de Oliveira, B.M.S., Oliveira, J.W.S., Vieira, J.S., Blank, A.F., Bacci, L., 2018. Apis mellifera (Insecta: Hymenoptera) in the target of neonicotinoids: A one-way ticket? Bioinsecticides can be an alternative. Ecotoxicol. Environ. Saf. 163, 28-36. https://doi.org/10.1016/j.ecoenv.2018.07.048

Schäfer, R.B., von der Ohe, P.C., Rasmussen, J., Kefford, B.J., Beketov, M.A., Schulz, R., Liess, M., 2012. Thresholds for the Effects of Pesticides on Invertebrate Communities and Leaf Breakdown in Stream Ecosystems. Environ. Sci. Technol. 46, 5134-5142. https://doi.org/10.1021/es2039882

Schmickl, T., Crailsheim, K., 2007. HoPoMo: A model of honeybee intracolonial population dynamics and resource management. Ecol. Modell. 204, 219-245. https://doi.org/10.1016/j.ecolmodel.2007.01.001

Schmolke, A., Abi-Akar, F., Hinarejos, S., 2019. Honey bee colony-level exposure and effects in realistic landscapes: An application of BEEHAVE simulating clothianidin residues in corn pollen. Environ Toxicol Chem 38, 423-435. https://doi.org/10.1002/etc.4314

Schneider, C.W., Tautz, J., Grünewald, B., Fuchs, S., 2012. RFID Tracking of Sublethal Effects of Two Neonicotinoid Insecticides on the Foraging Behavior of Apis mellifera. PLoS ONE 7, e30023. https://doi.org/10.1371/journal.pone.0030023

Schneider, S., Eisenhardt, D., Rademacher, E., 2012. Sublethal effects of oxalic acid on Apis mellifera (Hymenoptera: Apidae): changes in behaviour and longevity. Apidologie 43, 218-225. https://doi.org/10.1007/s13592-011-0102-0

Schricker, B., Stephen, W.P., 1970. The Effect of Sublethal Doses of Parathion on Honeybee Behaviour. I. Oral Administration and the Communication Dance. J. Apic. Res. 9, 141-153. https://doi.org/10.1080/00218839.1970.11100261

Schürch, R., Grüter, C., 2014. Dancing Bees Improve Colony Foraging Success as Long-Term Benefits $\begin{array}{llllll}\text { Outweigh Short-Term } & \text { Costs. PLoS } 104660 .\end{array}$ https://doi.org/10.1371/journal.pone.0104660

Sgolastra, F., Medrzycki, P., Bortolotti, L., Maini, S., Porrini, C., Simon-Delso, N., Bosch, J., 2020. Bees and pesticide regulation: Lessons from the neonicotinoid experience. Biol. Conserv. 241, 108356. https://doi.org/10.1016/j.biocon.2019.108356

Sherman, G., Visscher, P.K., 2002. Honeybee colonies achieve fitness through dancing. Nature 419, 920-922. https://doi.org/10.1038/nature01127

Shi, J., Yang, H., Yu, L., Liao, C., Liu, Y., Jin, M., Yan, W., Wu, X.B., 2020. Sublethal acetamiprid doses negatively affect the lifespans and foraging behaviors of honey bee (Apis mellifera $\mathrm{L}$.) workers. Sci. Total Environ. 738, 139924. https://doi.org/10.1016/j.scitotenv.2020.139924

Siefert, P., Hota, R., Ramesh, V., Grünewald, B., 2020. Chronic within-hive video recordings detect altered nursing behaviour and retarded larval development of neonicotinoid treated honey bees. Sci. Rep. 10, 8727. https://doi.org/10.1038/s41598-020-65425-y

Siviter, H., Koricheva, J., Brown, M.J.F., Leadbeater, E., 2018. Quantifying the impact of pesticides on learning and memory in bees. J. Appl. Ecol. 55, 2812-2821. https://doi.org/10.1111/13652664.13193 
Steffan-Dewenter, I., Kuhn, A., 2003. Honeybee foraging in differentially structured landscapes. Proc. R. Soc. Lond. B. 270, 569-575. https://doi.org/10.1098/rspb.2002.2292

Storck, V., Karpouzas, D.G., Martin-Laurent, F., 2017. Towards a better pesticide policy for the European Union. Science of The Total Environment 575, 1027-1033. https://doi.org/10.1016/j.scitotenv.2016.09.167

Straub, L., Villamar-Bouza, L., Bruckner, S., Chantawannakul, P., Gauthier, L., Khongphinitbunjong, K., Retschnig, G., Troxler, A., Vidondo, B., Neumann, P., Williams, G.R., 2016. Neonicotinoid insecticides can serve as inadvertent insect contraceptives. Proc. R. Soc. B. 283, 20160506. https://doi.org/10.1098/rspb.2016.0506

Streit, S., Bock, F., Pirk, C.W.W., Tautz, J., 2003. Automatic life-long monitoring of individual insect behaviour now possible. Zoology 106, 169-171. https://doi.org/10.1078/0944-2006-00113

Suchail, S., Guez, D., Belzunces, L., 2001. Discrepancy between acute and chronic toxicity induced by imidacloprid and its metabolites in Apis mellifera. Environ. Toxicol. Chem. 20, 2482-2486. https://doi.org/10.1002/etc.5620201113

1135 Taylor, K.S., Waller, G.D., Crowder, L.A., 1987. Impairment of a classical conditioned response of the honey bee (Apis mellifera L.) By sublethal doses of synthetic pyrethroid insecticides. Apidologie 18, 243-252. https://doi.org/10.1051/apido:19870304

Teeters, B.S., Johnson, R.M., Ellis, M.D., Siegfried, B.D., 2012. Using video-tracking to assess sublethal effects of pesticides on honey bees (Apis mellifera L.). Environ. Toxicol. Chem. 31, 1349-1354. https://doi.org/10.1002/etc.1830

Thompson, H.M., 2003. Behavioural Effects of Pesticides in Bees - Their Potential for Use in Risk Assessment. Ecotoxicology 12, 317-330. https://doi.org/10.1023/A:1022575315413

Thompson, H.M., Maus, C., 2007. The relevance of sublethal effects in honey bee testing for pesticide risk assessment. Pest. Manag. Sci. 63, 1058-1061. https://doi.org/10.1002/ps.1458

1145 Tison, L., Hahn, M.-L., Holtz, S., Rößner, A., Greggers, U., Bischoff, G., Menzel, R., 2016. Honey bees' behavior is impaired by chronic exposure to the neonicotinoid thiacloprid in the field. Environ. Sci. Technol. 50, 7218-7227. https://doi.org/10.1021/acs.est.6b02658

Tison, L., Holtz, S., Adeoye, A., Kalkan, Ö., Irmisch, N.S., Lehmann, N., Menzel, R., 2017. Effects of sublethal doses of thiacloprid and its formulation Calypso ${ }^{\circledR}$ on the learning and memory performance of honey bees. J. Exp. Biol. 220, 3695-3705. https://doi.org/10.1242/jeb.154518

Tofilski, A., Chuda-Mickiewicz, B., Czekońska, K., Chorbiński, P., 2012. Flow cytometry evidence about sperm competition in honey bee (Apis mellifera). Apidologie 43, 63-70. https://doi.org/10.1007/s13592-011-0089-6

Tong, L., Nieh, J.C., Tosi, S., 2019. Combined nutritional stress and a new systemic pesticide (flupyradifurone, Sivanto ${ }^{\circledR}$ ) reduce bee survival, food consumption, flight success, and thermoregulation. Chemosphere https://doi.org/10.1016/j.chemosphere.2019.124408

Torres, D.J., Ricoy, U.M., Roybal, S., 2015. Modeling Honey Bee Populations. PLoS ONE 10, e0130966. https://doi.org/10.1371/journal.pone.0130966

1160 Tosi, S., Burgio, G., Nieh, J.C., 2017. A common neonicotinoid pesticide, thiamethoxam, impairs honey bee flight ability. Sci. Rep. 7, 1201. https://doi.org/10.1038/s41598-017-01361-8

Tosi, S., Nieh, J.C., 2017. A common neonicotinoid pesticide, thiamethoxam, alters honey bee activity, motor functions, and movement to light. Sci. Rep. 7, 15132. https://doi.org/10.1038/s41598017-15308-6

1165 Urlacher, E., Monchanin, C., Rivière, C., Richard, F.-J., Lombardi, C., Michelsen-Heath, S., Hageman, K.J., Mercer, A.R., 2016. Measurements of Chlorpyrifos Levels in Forager Bees and Comparison with Levels that Disrupt Honey Bee Odor-Mediated Learning Under Laboratory Conditions. J. Chem. Ecol. 42, 127-138. https://doi.org/10.1007/s10886-016-0672-4

Vandame, R., Meled, M., Colin, M.-E., Belzunces, L.P., 1995. Alteration of the homing-flight in the honey bee Apis mellifera L. exposed to sublethal dose of deltamethrin. Environ. Toxicol. Chem. 14, 855-860. https://doi.org/10.1002/etc.5620140517

vanEngelsdorp, D., Tarpy, D.R., Lengerich, E.J., Pettis, J.S., 2013. Idiopathic brood disease syndrome and queen events as precursors of colony mortality in migratory beekeeping operations in the eastern United States. Prev. Vet. Med. 108, 225-233. https://doi.org/10.1016/j.prevetmed.2012.08.004 
Walsh, E.M., Sweet, S., Knap, A., Ing, N., Rangel, J., 2020. Queen honey bee (Apis mellifera) pheromone and reproductive behavior are affected by pesticide exposure during development. Behav Ecol Sociobiol 74, 33. https://doi.org/10.1007/s00265-020-2810-9

Wang, M., Braasch, T., Dietrich, C., 2020. Reduction of variability for the assessment of side effects of toxicants on honeybees and understanding drivers for colony development. PLoS ONE 15, e0229295. https://doi.org/10.1371/journal.pone.0229295

Wario, F., Wild, B., Couvillon, M.J., Rojas, R., Landgraf, T., 2015. Automatic methods for long-term tracking and the detection and decoding of communication dances in honeybees. Front. Ecol. Evol. 3. https://doi.org/10.3389/fevo.2015.00103

1185

Williams, G.R., Troxler, A., Retschnig, G., Roth, K., Yañez, O., Shutler, D., Neumann, P., Gauthier, L., 2015. Neonicotinoid pesticides severely affect honey bee queens. Sci. Rep. 5, 14621. https://doi.org/10.1038/srep14621

Williams, J.R., Swale, D.R., Anderson, T.D., 2020. Comparative effects of technical-grade and formulated chlorantraniliprole to the survivorship and locomotor activity of the honey bee, Apis mellifera (L.). Pest. Manag. Sci. https://doi.org/10.1002/ps.5832

Williamson, S.M., Moffat, C., Gomersall, M.A.E., Saranzewa, N., Connolly, C.N., Wright, G.A., 2013. Exposure to acetylcholinesterase inhibitors alters the physiology and motor function of honeybees. Front. Physio. 4, 13. https://doi.org/10.3389/fphys.2013.00013

Williamson, S.M., Willis, S.J., Wright, G.A., 2014. Exposure to neonicotinoids influences the motor function of adult worker honeybees. Ecotoxicology 23, 1409-1418. https://doi.org/10.1007/s10646-014-1283-x

Woodcock, B.A., Bullock, J.M., Shore, R.F., Heard, M.S., Pereira, M.G., Redhead, J., Ridding, L., Dean, H., Sleep, D., Henrys, P., Peyton, J., Hulmes, S., Hulmes, L., Sárospataki, M., Saure, C., Edwards, M., Genersch, E., Knäbe, S., Pywell, R.F., 2017. Country-specific effects of neonicotinoid pesticides on honey bees and wild bees. Science 356, 1393-1395. https://doi.org/10.1126/science.aaa1 190

Woyke, J., 1989c. Results of instrumental insemination, in: Moritz R.F.A., The Instrumental Insemination of the Queen Bee. Bucharest, pp. 93-103.

Wu-Smart, J., Spivak, M., 2016. Sub-lethal effects of dietary neonicotinoid insecticide exposure on honey bee queen fecundity and colony development. Sci. Rep. 6, 32108. https://doi.org/10.1038/srep32108

Yang, E.-C., Chang, H.-C., Wu, W.-Y., Chen, Y.-W., 2012. Impaired Olfactory Associative Behavior of Honeybee Workers Due to Contamination of Imidacloprid in the Larval Stage. PLoS ONE 7, e49472. https://doi.org/10.1371/journal.pone.0049472

1210 Yang, E.C., Chuang, Y.C., Chen, Y.L., Chang, L.H., 2008. Abnormal foraging behavior induced by sublethal dosage of imidacloprid in the honey bee (Hymenoptera: apidae). J. Econ. Entomol. 101, 1743-1748. https://doi.org/10.1603/0022-0493-101.6.1743

Yániz, J.L., Silvestre, M.A., Santolaria, P., 2020. Sperm Quality Assessment in Honey Bee Drones. Biology 9, 174. https://doi.org/10.3390/biology9070174

1215 Zhang, S.W., Lehrer, M., Srinivasan, M.V., 1999. Honeybee memory: navigation by associative grouping and recall of visual stimuli. Neurobiol. Learn. Mem. 72, 180-201. https://doi.org/10.1006/nlme.1998.3901

Zhang, Z.Y., Li, Z., Huang, Q., Yan, W.Y., Zhang, L.Z., Zeng, Z.J., 2020a. Honeybees (Apis mellifera) modulate dance communication in response to pollution by imidacloprid. J. Asia Pac. Entomol. 23, 477-482. https://doi.org/10.1016/j.aspen.2020.03.011

Zhang, Z.Y., Li, Z., Huang, Q., Zhang, X.W., Ke, L., Yan, W.Y., Zhang, L.Z., Zeng, Z.J., 2020b. Deltamethrin impairs honeybees (Apis mellifera) dancing communication. Arch. Environ. Contam. Toxicol. 78, 117-123. https://doi.org/10.1007/s00244-019-00680-3

Zioga, E., Kelly, R., White, B., Stout, J.C., 2020. Plant protection product residues in plant pollen and nectar: a review of current knowledge. Environ. Res. 109873. https://doi.org/10.1016/j.envres.2020.109873 


\section{Figure legends}

1230

Figure 1. Bibliometric of honeybee toxicological research studies using individual-based behavioral and reproductive endpoints. (A) Cumulative number of publications per year on behavioral and reproductive endpoints. The $\mathrm{Y}$-axis on the left refers to the number of publications per endpoints (colored lines) and the $\mathrm{Y}$-axis on the right to total number of publications (thick black line).

1235 The X-axis refers to the years of publication. (B) Breakdown of pesticide types (left) and endpoints (right). The thickness of each line connecting a pesticide type to a given endpoint is proportional to the number of studies.

Figure 2. Average scores ( \pm s.e.) assigned by all of the stakeholders to each of the four test methods 1240 for the five assessment criteria considered. For each of the test methods, score ranges from 0 (low) to 5 (high); $\mathrm{n}=23$ participants. 
A

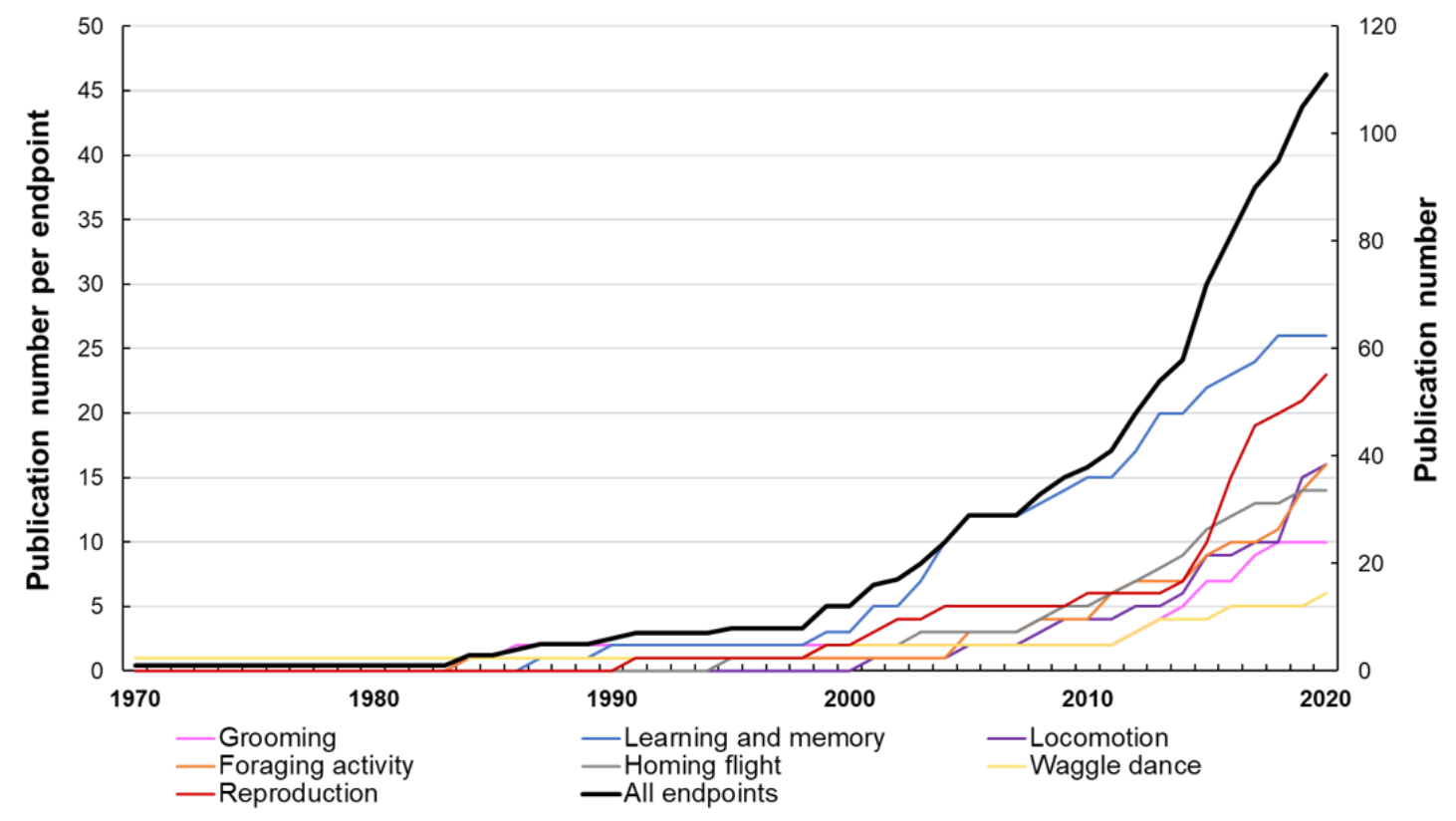

B

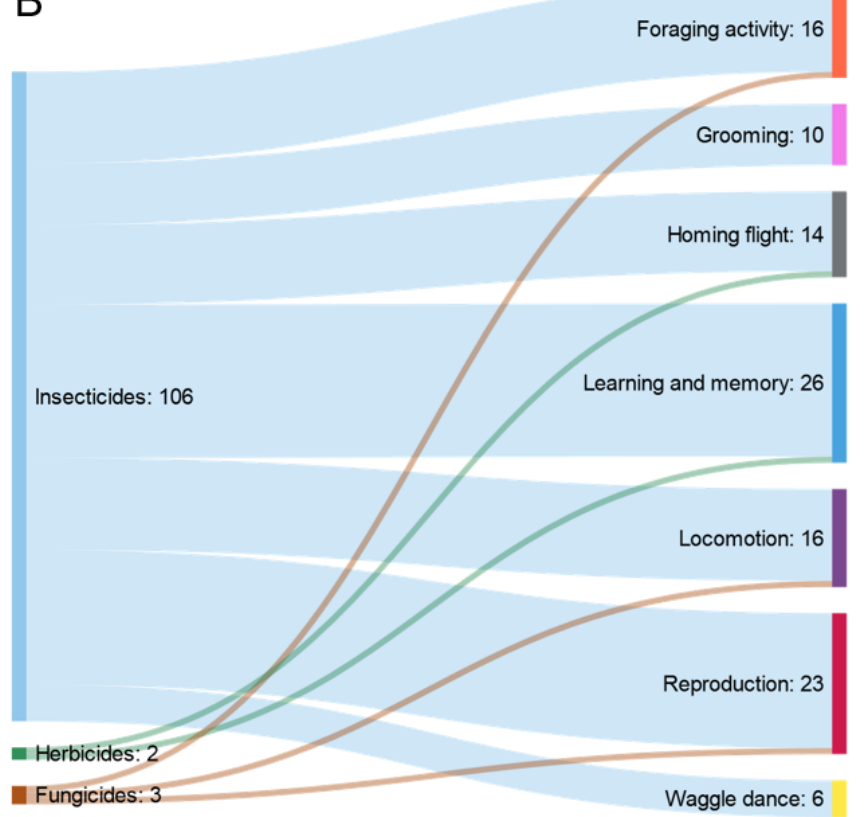


Figure 2

PER

(laboratory)

Ecological relevance $\longrightarrow 1,9$

Reproducibility

Robustness

Sensitivity

Simplicity
Foraging activity (semi-field)

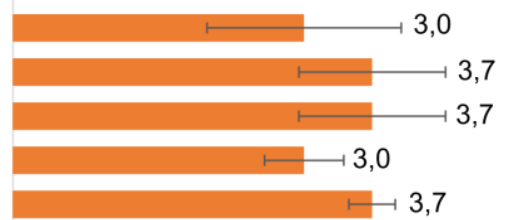

Waggle dance

(semi-field or field)

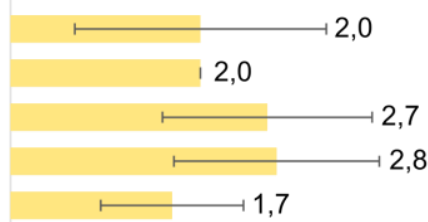

Homing flight

(field)

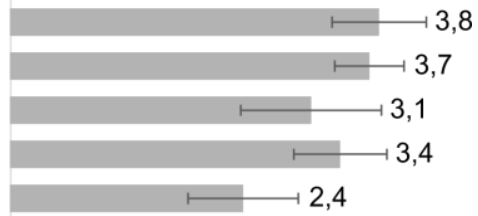

